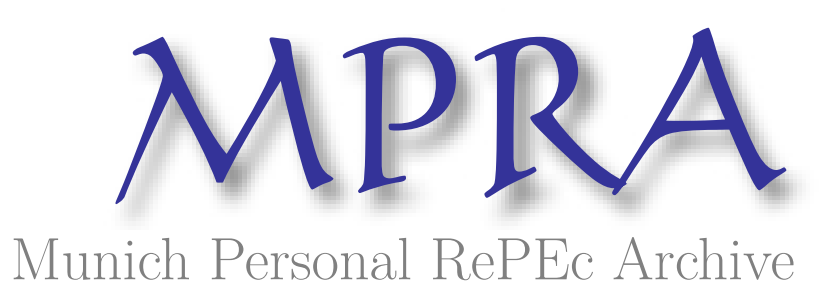

\title{
Complements and Substitutes in Sequential Auctions: The Case of Water Auctions
}

\author{
Donna, Javier and Espin-Sanchez, Jose \\ Ohio State University, Northwestern
}

17 February 2014

Online at https://mpra.ub.uni-muenchen.de/55079/

MPRA Paper No. 55079, posted 09 Apr 2014 19:43 UTC 


\title{
Complements and Substitutes in Sequential
}

\section{Auctions: The Case of Water Auctions*}

\author{
Javier Donna ${ }^{\dagger} \quad$ and José-Antonio Espín-Sánchez \\ The Ohio State University \\ Northwestern University
}

First version: December 10, 2010

This version: February 17, 2014

\footnotetext{
${ }^{*}$ We are indebted to our advisors, Joel Mokyr and Rob Porter, for helpful discussions, guidance, and support. We are also grateful to the members of our dissertation committee, Meghan Busse, Regina Graffe, Aviv Nevo, and Florian Zettelmeyer, for advice and encouragement. Discussions with Jason Blevins, Jia-Young (Mike) Fu, Matt Gunden, Jim Peck, Bill Rogerson, Ron Siegel, and Alex Torgovitsky, as well as seminar participants at the International Industrial Organization Conference (2013), the Jornadas de Economia Industrial (XXVII ${ }^{t h}$ edition), the Meetings of the European Association for Research in Industrial Economics (EARIE 2012), the North American Summer Meetings of the Econometric Society (2012), the Second Annual UTDT Economics Conference, the World Economic History Congress ( $\mathrm{XVI}^{t h}$ edition), the Midwest Economics Association Annual Meeting (2013), Aarhus University, Analysis Group, Arizona State University, Bates White, Charles River Associates, Centro de Estudios Monetarios y Financieros (CEMFI), Compass Lexecon, Johns Hopkins University, Northwestern University (Industrial Organization and History Workshops), The Ohio State University, and Universidad Carlos III have greatly benefited this work. We would also like to express our gratitude to Fernanda Donna and Antonio Espin for superb research assistance, to the librarians from the archive of Mula for valuable help in accessing the historical files, and to Maja Butovich, Elizabeth Lenaghan, and Melissa Petruzzello for editorial advice. We thank the AEMET for providing us with the meteorological data. José-Antonio Espín-Sánchez also acknowledges financial support from Fundacion Caja Madrid. This paper was part of Javier Donna's Ph.D. dissertation at Northwestern University. All errors are our own. The paper can be downloaded at http://www.jdonna.org/research. The Web Appendix for this paper is http://www.jdonna.org/water-auctions-web.

$\dagger$ The Ohio State University, Department of Economics, 1945 N. High St., 417 Arps Hall, Columbus, OH 43210. Email: donna.1@osu.edu. Phone: 614-688-0364.

${ }^{\ddagger}$ Northwestern University, Department of Economics, 302 Arthur Andersen Hall, 2001 Sheridan Road, Evanston, IL 60208, joseespin2013@u.northwestern.edu.
} 


\begin{abstract}
We use data on sequential water auctions to estimate demand when units are complements or substitutes. A sequential English auction model determines the estimating structural equations. When units are complements, one bidder wins all units by paying a high price for the first unit, thus deterring others from bidding on subsequent units. When units are substitutes, different bidders win the units with positive probability, paying prices similar in magnitude, even when the same bidder wins all units. We recover individual demand consistent with this stark pattern of outcomes and confirm it is not collusive, but consistent with non-cooperative behavior. Demand estimates are biased if one ignores these features.
\end{abstract}

JEL Codes: D44, C13, L10, L40

KeYwords: Auctions, Structural Demand Estimation, Market Structure, Competition, Collusion

$\begin{array}{ll}\text { Javier Donna } & \text { José-Antonio Espín-Sánchez } \\ \text { Department of Economics } & \text { Department of Economics } \\ \text { The Ohio State University } & \text { Northwestern University } \\ 1945 \text { N High St, 417 Arps Hall } & \text { 2001 Sheridan Rd, 302 AAH } \\ \text { Columbus, OH 43210 } & \text { Evanston, IL 60208 } \\ \text { Phone: 614-688-0364 } & \text { Phone: 847-471-2755 } \\ \text { Email: donna.1@osu.edu } & \text { Email: joseespin2013@u.northwestern.edu }\end{array}$




\section{Introduction}

This paper investigates sequential auctions in which buyers' preferences for multiple units exhibit both sunk costs and decreasing marginal returns. Sunk costs and decreasing returns are important because they affect the relationship among the valuation of subsequent units, determining bidder behavior and price dynamics. Price dynamics are central in relating observed bids to the underlying distributions that characterize individual demand, which is fundamental to discuss positive and normative questions. Greater variation in prices caused by a high sunk cost, for instance, will affect even relatively simple tasks such as measuring the dispersion in individuals' private valuations. Moreover, a competitive environment in such a case could be incorrectly interpreted as collusive.

Depending on the importance of sunk costs relative to decreasing marginal returns of sequential units, these units could be complements (when the marginal utility of subsequent units is greater than the marginal utility of the first unit) or substitutes (when the marginal utility of subsequent units is lower than the marginal utility of the first unit). The existing literature, although abundant, has provided little empirical evidence on the effect that, by creating complementarities or substitutabilities, the valuation of subsequent units has on bidder strategies and price behavior in sequential auctions. ${ }^{1}$

The main reason for this lack of evidence is insufficient variation in the degree of complementarity (in our setting, sunk costs relative to decreasing returns) required to perform the empirical investigation. Our aim is to address this empirical gap. To that end, we develop an economic model to assess the relative importance of sunk costs and decreasing returns in bidding behavior. Ours is the first empirical paper where sequential units of the same good serve as either complements or substitutes within the same market.

\footnotetext{
${ }^{1}$ In addition to the literature on sequential independent objects (Ashenfelter 1989; Ashenfelter and Genesove 1992), the relationship between auctioned objects has also been studied by a number of authors for the case of either complements (Branco 1997; Gandal 1997) or substitutes (Black and De Meza 1992; Liu 2011). Albeit more scarce, models encompassing the possibility of both complementarities and substitutabilities have been investigated when analyzing how this feature relates to the auction format (Jeitschko and Wolfstetter 2002; Jofre-Bonet and Pesendorfer 2012) or, outside the auction literature, when analyzing print and online newspapers to study the value of new goods (Gentzkow 2007). Unlike this prior literature, we examine, in an English-auction setting, how the degree of complementarity, as determined by the importance of sunk costs relative to decreasing returns, affects price patterns by endogenizing the number of bidders with the introduction of an arbitrary small participation cost as in McAfee and McMillan (1987), Engelbrecht-Wiggans (1993); and von der Fehr (1994).
} 
We examine a unique panel data set on sequential water auctions from a self-governed community of farmers in southern Spain (Mula, Murcia). We estimate our model to recover the structural parameters and the distribution of private valuations. Our study of sequential auctions exploits a unique scenario to analyze a stark pattern of outcomes not previously documented in the literature. Sometimes, winning prices exhibit a standard competitive pattern, where regardless of whether the same or different bidders (farmers) win the sequential units, winning prices are similar in magnitude. ${ }^{2}$ Other times, one farmer wins all the units; this farmer pays a high price for the first unit, deterring other farmers from entering subsequent auctions, thus paying a very low price for the remaining units. We call this the deterrence effect. We show that this pattern of outcomes is consistent with a non-cooperative equilibrium, where the observed price dynamics are not collusive, but competitive.

The data for our analysis consist of individual winning bids and auction covariates, which includes the amount of rainfall. The basic unit for sale is the right to use three hours of water for irrigation (432,000 liters). For each weekday, eight units are sold sequentially for each schedule: four for daytime (7AM-7PM) and four for nighttime (7PM-7AM) irrigation. Same-day (or same-night) units are not conditional-independent due to the presence of sunk costs. Thus, the relevant unit of analysis for investigating individuals' demand and the pattern of outcomes is four-unit auctions. Observing the identity of the winner allow us to estimate the model, as outlined in Section 3. Local weather conditions determine the relevant agricultural irrigation technology and, hence, water demand. Additionally, as summers have little rainfall compared to winters, the presence of seasonalities provide us with the necessary variation in sunk costs relative to decreasing returns (varying the degree of complementarity or substitutability by season) to perform the empirical investigation.

The interpretation of the data based on our economic model is fundamental to our structural approach. We model the environment as a sequential (ascending price) English-auction along the lines of Engelbrecht-Wiggans (1993) and von der Fehr (1994) in which bidders, by incurring a participation cost, decide whether to attend each sale. We focus on the symmet-

\footnotetext{
${ }^{2}$ Declining prices for identical objects in this type of setting is an empirical regularity known as the declining price anomaly, which has been broadly studied in the literature and was first documented by Ashenfelter (1989) in his seminal paper. Under stylized conditions the price should follow a martingale. However, under specific assumptions, like risk aversion, the price should follow a super-martingale.
} 
ric conditional-independent private values (CIPV) paradigm that has dominated the prior literature (Donald and Paarsch 1996). A sunk cost is incurred for the first unit bought, and decreasing marginal returns are present for subsequent units. The rationale for this is found in our empirical setting. First, because water flows through a channel dug into the ground, some water is lost when the channel is dry (the first unit), but the loss is negligible for subsequent units. Engineers have estimated that $20 \%$ of the water of the first unit that travels through a dry channel is lost (see González-Castaño and Llamas-Ruiz 1991). Second, given that the amount of land that needs to be irrigated is fixed, subsequent units of water exhibit decreasing marginal returns.

The relative importance of the sunk cost and the decreasing marginal returns generates a trade-off, whereby buyers' bidding strategies depend on whether different units are complements or substitutes. When goods are complements, the same bidder wins all the objects: he pays a high price for the first unit equal to his valuation for the whole bundle (four times the second highest valuation for the first unit, adjusted for the complementarity effect and participation cost), and he thus deters others from bidding on the remaining three units, for which he pays a very low price (close to zero). ${ }^{3}$ The resulting non-cooperative equilibrium price pattern, along with the same bidder winning all the units, may lead to an incorrect collusive interpretation. When goods are substitutes, different bidders win the objects with positive probability, paying prices similar in magnitude, even when the same bidder wins all the objects. We provide empirical evidence for participation and sunk costs, key features of our model. We argue that bidders are better informed than the seller, whose mechanism ignores bidder preferences for multiple units. Nevertheless, a sequential English auction achieves (ex-ante) efficiency. ${ }^{4}$ The simplicity of the mechanism reduces costs associated with its implementation, with the additional advantage that bidders are not required to reveal their marginal valuations.

The price patterns that our model predicts in each regime (complements or substitutes) provide us with a straightforward empirical method to determine the regime under which the

\footnotetext{
${ }^{3}$ For clarity, we refer to each farmer as "he" although occasionally is a woman who bids.

${ }^{4}$ Ex-ante and ex-post efficiency are not equivalent due to the presence of participation costs. Neither one implies the other. Moreover, in our model there is no mechanism that achieves ex-post efficiency. Stegeman (1996) discusses the single-unit case. In our model, when goods are complements, the proof for efficiency is analogous to the single-unit case; the analysis when goods are substitutes is more cumbersome.
} 
game is being played: when goods are complements, very low prices are paid by the same winner (the winner of the first unit) for the second, third, and fourth units.

Aside from the particular features of our specification, our identification exercise is closest to that of Athey and Haile (2002). Using a parametric distribution specification along with the English structure for the auction, we construct the likelihood of our model and we use maximum likelihood to estimate the parameters of the distribution of private valuations. To estimate the remaining parameters (sunk cost and decreasing marginal returns) we form moment conditions based on the structural equations of the model. We infer participation costs using data from auctions in which bidders were present, but no one placed bids.

Our empirical work establishes three main results. First, we recover individual demand - characterized by private valuations and the model's structural parameters - that is consistent with the described price patterns, and the deterrence effect in particular. Second, the equilibrium price dynamics are consistent with competitive behavior. Non-cooperative behavior is not only consistent with the deterrence effect, but also predicts such price differentials. Incentives to deviate from a collusive strategy are higher in the spring/summer (when the water is more valuable). However, it is in spring/summer when we observe this behavior more often. Finally, we show that estimates that ignore the importance of participation and sunk costs will be biased. We test whether price variations, conditional on covariates, are better explained by our proposed model or a standard English-auction model without participation costs, using that the latter is encompassed by the former. The approach of Haile and Tamer (2003), that relies on two basic behavioral assumptions, provides a robust structural framework for inference. These minimal assumptions are not satisfied in the present context. We also discuss how Haile and Tamer's structure can be interpreted in the current setting.

\section{Contributions and Related Literature}

In this subsection we describe the related literature and highlight how our paper contributes to the current body of work. While this paper includes new theoretical results, it is most similar to the empirical literature on sequential auctions with multi-unit demand investigating strategic bidding's predictions. While most of the literature do not consider participation 
costs in their analyses, we show that the presence of participation costs affect the equilibrium outcomes; we then use our model to partially identify participation costs and estimate informative bounds.

In his seminal paper, Weber (1983) finds that in a sequential auctions model with singleunit demand for identical objects, the sequence of prices follows a martingale (same expected prices). However, relatively slight modifications to Weber's model lead to different conclusions. For example, including risk-aversion in his model generates lower expected prices for later objects. In this case, expected utility (not expected price) follows a martingale, as the expected utility is lower for a risk averse bidder. McAfee and Vincent (1993) found that declining prices in equilibrium requires non-decreasing absolute risk aversion. Sequential auctions for different objects that are stochastically identical have also been studied (Benhardt and Scoones 1994; Engelbrecht-Wiggans 1994). In those cases, objects are identical ex-ante but not after uncertainty has been resolved. The relationship between early and latter objects is broken because of the stochastic component: the demand for latter objects is lower than for early ones. Thus, the strategical incentive for bidding lower for early objects disappears. Contrary to our case, these models do not allow for multi-unit demand. ${ }^{5}$

While the theoretical literature has studied price dynamics and the relationship between sequentially auctioned goods, there is no precedent that deals with cases when both complementarities and substitutabilities (generated by sunk cost and decreasing returns in our empirical setting) are present with participation costs. ${ }^{6}$ Similar evidence to the one we de-

\footnotetext{
${ }^{5}$ The literature in multi-unit auctions can be divided into sequential auctions, in which the auctioneer sells the units following a series of sequential steps using a single-unit auction each time, and simultaneous auctions, in which the auctioneer uses a complex auction mechanism to allocate all units simultaneously (for recent contributions see Kastl 2011, who investigates bidders submitting step functions as their bids in multi-unit treasury bills auctions, and Reguant 2013, who studies complementarity bidding mechanisms used in wholesale electricity auctions). Implementing a simultaneous auction requires a strong commitment from the auctioneer either to not renege in the promised mechanism, or to use the information elicited in the process to demand a higher price for the good. This also imposes technical difficulties in the way bidders frame their contingent bids (Cramton, Shoham and Steinberg 2006). Neither of these conditions are satisfied in our setting. Hortaçsu (2011) discusses recent progress in the empirical study of multi-units auctions. See Kagel and Levin (2001) for an experimental investigation when bidders demand multiple units in sealed bid and ascending auctions.

${ }^{6}$ Hendricks and Porter (2007) present a comprehensive review of the theoretical and empirical literature on auctions emphasizing their connection, and the different approaches followed by researchers in practice. For standard IPV parametric models, Donald and Paarsch (1996) provide an early discussion on identification, estimation, and inference under this paradigm, while Athey and Haile (2002) extensively discuss identification of different models, and derive testable restrictions that allow discrimination between models. For first-price sealed-bid auction models within the independent private value paradigm, Guerre, Perrigne and Vuong (2000) show that the underlying distribution of bidders' private values is nonparametrically identified from observed
} 
scribe in Subsection C.2 in the Online Appendix has been broadly discussed in the empirical auctions literature. Early works have documented declining or downward price trends in sequential wine auctions (Ashenfelter 1989; McAfee and Vincent 1993) and the real-state market (Ashenfelter and Genesove 1992). In our setting the presence of complementarities and substitutabilities within the same market generate a stark pattern of outcomes not documented in the literature before: sometimes (when goods are substitutes), winning prices exhibit a standard competitive pattern, where regardless of whether the same or different bidders win the sequential units, winning prices are similar in magnitude; other times (when goods are complements), the same bidder wins all units by paying a high price for the first unit, thus deterring others from bidding on subsequent units. We show that this pattern of outcomes is consistent with a competitive market structure.

Several authors have studied cases of either complements due to synergies among auctioned goods, or substitutes due to decreasing marginal utility (Black and De Meza 1992; Branco 1997; Liu 2011). For instance, Branco finds expected decreasing prices for complements. In that model, individuals bid above their value in early auctions because there is an option value for doing so. In latter auctions, and when early objects have already been assigned, the winner bids aggressively, but the losers bid their residual value. Thus, the price for later units reflects the willingness to pay from a bidder without synergies. This value is lower than the price paid for earlier units that reflect both the willingness to pay from an individual without synergies and the option value.

Selling goods in a bundle increases sellers' revenue when goods are complements (Palfrey 1983; Levin 1997, Armstrong 2000). Our setting differs from these in that we consider sequential auctions instead of simultaneous. ${ }^{7}$ Numerous empirical studies have highlighted the

bids and the number of actual bidders. For interdependent costs, asymmetric bidders, and statistically dependent private information, Somaini (2013) shows that the joint distribution of private information and each bidder's full information expected cost is nonparametrically identified from the distribution of bids conditional on observable cost shifters. For English auctions with correlated private values, Aradillas-López, Gandhi and Quint (2013) exploit variation in the number of bidders to nonparametrically identify bounds on seller's profit and bidders' surplus (rather than the joint distribution of private valuations). Bajari, Houghton and Tadelis (2013) empirically investigate ex post adaptation costs that result from incomplete contracts in highway procurement in California.

${ }^{7}$ See Milgrom (2000) and Ausubel (2004) for recent contributions to this literature. Edelman, Ostrovsky and Schwarz (2007) study the properties of a "generalized English auction" (used to sell Internet advertisements) and show their proposed mechanism has a unique equilibrium. Kagel and Levin (2005) experimentally investigate multi-unit demand auctions with synergies, and compare behavior in sealed-bid and ascending-bid uniform-price auctions. See Kagel (1995) for a survey on laboratory experimental auction markets. 
importance of complementarities. They arise in different industries such as defense contracts (in Anton and Yao 1987 complementarities emerge in sequential competition due to higher experience that reduces costs), sequential cable television license auctions (Gandal 1997), sequential electricity auctions (in Wolfram 1998 the start-up price generates complementarities in electricity generation between adjacent time periods), sequential procurement auctions for school milk contracts where, similar to our analysis, complementarities arise due to the presence of sunk investments (Pesendorfer 2000), or between adjacent school milk contracts (Marshall et al. 2006).

Regarding substitutabilities, Liu's model, for instance, shows that competition for earlier goods is lower than for latter ones. Therefore, winning an early auction generates an externality on other bidders (because of the competition they face in the future). In later stages, this effect is smaller because there are less goods in which a loser can take advantage of the resulting competition. Thus, competition (and prices paid by the winners) will be greater. In the last auction the externality effect disappears, and each person bids their own valuation for that last good. Substitutabilities also arise, as in our case, when the value of sequential goods fall (in the number of acquired units) generally because of decreasing returns and limited capacity. Substitutabilities are a major component in several industries such as sequential highway construction procurement auctions (Jofre-Bonet and Pesendorfer 2003 estimate a repeated auction game under the presence of capacity constraints with bidder asymmetry), sequential timber auctions (List, Millimet and Price 2004), or sequential cattle auctions (Zulehner 2009).

Before we advance to the description of our model, it is important to note that while prior investigations on the relationship between sequential auctions and the complements or substitutes property are more scarce (Jeitschko and Wolfstetter 2002; Jofre-Bonet and Pesendorfer 2012), their approaches show the importance of this feature. Jeitschko and Wolfstetter analyze optimal sequential auctions in a binary-valuations case. They find that English-auctions extract more rent than first-price auctions. ${ }^{8}$ Our model differs as we consider the class of continuous valuation distributions. Along with a literature review that provides a comprehensive guide on the methods and applications in the subject, Jofre-Bonet and Pesendorfer

\footnotetext{
${ }^{8}$ Recall that the English-auction is optimal among a general class of sequential auctions (Lopomo 1998).
} 
propose a different set-up in their model of sequential auctions that also encompasses both complementarities and substitubilities among the goods auctioned (in the sense that an object's value increases or decreases with the number of items already acquired). They find that while first-price auctions give greater revenue than a second-price (English) auctions when the goods are substitutes, the opposite is true for complements. Both mechanisms are efficient in this model. Their predictions about price trend are consistent with previous findings. Contrary to our analysis with participation costs, where buyers are better informed than the seller, they examine buyers' procurement auctions in a two period auction game where sellers have private information about their costs. Finally, although different from the strategy used in this paper, an early influential investigation on how interdependencies among the objects auctioned affect auction's outcome has been studied by Hendricks and Porter (1988), where they analyze auctions for drainage leases and show that better informed firms (who hold neighboring tracts to the drainage tracts that were auctioned) earned higher rents than uninformed ones.

This paper makes a methodological contribution by developing a structural empirical model of sequential English auctions with participation costs that allows units to complement or substitute within the same market; the model has distinguishable price pattern predictions in each regime. This feature allows us to determine the regime under which the game is being played using a straightforward empirical method: end-digit preferences. Similar to the work of Hendricks and Porter (1988) and Haile (2001) we show evidence inconsistent with the equilibrium predictions of standard models and in favor of our model that captures the specific features in our empirical setting (sunk costs, decreasing marginal returns, and participation costs). Not accounting for these features may lead to incorrectly interpret a competitive market as collusive.

In addition to recovering the structural parameters that characterize individual demand consistent with this stark pattern of outcomes and confirming it is consistent with noncooperative behavior, which are of interest to the literature on empirical auctions, we examine a market institution that was active and stable for eight centuries in a self-governed community of farmers in southern Spain. Understanding this strategic non-cooperative behavior of 
bidders in this stable market institution is of independent interest. ${ }^{9}$

We build upon the existing literature on participation costs and entry fees (McAfee and McMillan 1987; Engelbrecht-Wiggans 1993; von der Fehr 1994), by constructing our sequential English-auction model similar to that of Von der Fehr. However, our set up differs in that bidders are allowed to buy more than one unit of the good. Von der Fehr considers the case when goods are independent, and finds the same equilibrium as that in our complementarities case. We are not aware of any study analyzing the presence of both complementarities and substitutabilities when participation costs are present. Moreover, to our knowledge, we are the first to empirically investigate in the sequential auctions literature the case where sequential units of the same good may either complement or substitute within the same market. We do this by allowing the relative size of sunk cost and decreasing returns to vary across auctions. $^{10}$

In the next section we describe our theoretical model. Section 3 contains a description of the auction system and the data. We address the empirical regularities that serve as the foundation for the existence of two regimes (the size of sunk costs relative to decreasing marginal returns), and we show how the modeling assumptions fit our context. In Section 4 we discuss identification. Section 5 examines the estimation procedure, presents the results, and analyze the importance of sunk costs and the interpretation of complementarities. Finally, Section 6 concludes. The extension to the model where four units are sold and all proofs are in Section A in the Online Appendix. In Section B in the Online Appendix we show that regime determination is consistent with end-digit preferences.

\footnotetext{
${ }^{9}$ In the lead article of the first issue of the American Economic Review Coman (1911) provides an early discussion of the institution. For an extensive study of self-governed irrigation communities see Ostrom (1992).

${ }^{10}$ The presence of seasonalities in our empirical setting (due to rainfall and water requirements for farming) provides us the required variation for the empirical analysis.
} 


\section{The Model}

In this section we present the theoretical model. We first explain our strategy for using variation in the relative size of sunk costs and decreasing marginal returns to account for complementarities and substitutabilities among different units of the same good (water). We then proceed with the formal model. All proofs are in Section A in the Online Appendix.

A sunk cost is incurred only for the first unit bought while decreasing marginal returns are present for second to fourth units. The relative importance of the sunk cost and decreasing marginal returns generate a trade-off, whereby bidders coordinate their behavior based on whether different units are complements or substitutes. A simple way to show this intuition is by assuming that the initial sunk cost is proportional to the value of water, and decreasing marginal returns are linear in the number of units bought. Then, the marginal utility for bidder $i$ for each unit $u$ is:

$$
M U_{i}(u)=[1-\alpha \mathbf{1}\{u=1\}-\beta(u-1)] v_{i}
$$

where $v_{i}$, only known by bidder $i$, is a scalar that captures the valuation that the bidder assigns to a (complete) unit of water (when $\alpha=0$ we have $M U(1)=v_{i}$ ), $\alpha$ is a parameter that measures the sunk cost incurred when consuming the first unit bought $\left(M U(1)=(1-\alpha) v_{i}\right)$, $\beta$ is a parameter that measures the slope of decreasing marginal returns of subsequent units (when $\alpha=0$ we have $M U(u)=[1-\beta(u-1)] v_{i}$ ), and $\mathbf{1}\{\cdot\}$ is an indicator function.

\subsection{Set Up}

We proceed now to present the theoretical model. For each regime we derive the equations that we use later for the structural estimation. When goods are complements we compute the unique symmetric pure strategy perfect bayesian equilibrium. We also prove that the strategies played by every player in this equilibrium are dominant strategies. This strong result allows us to partially identify the parameters of the model without imposing further structure to the distribution of bidders' valuations. When goods are substitutes we compute necessary and sufficient conditions for equilibrium. Technical details and the solution of the model for this case are provided in Section A in the Online Appendix. 
We consider $v_{i}$ to be independent and identically distributed on the interval $\left[0, W_{i}\right]$, according to the increasing distribution function $F_{i}\left(v_{i}\right)$. We assume that $F_{i}\left(v_{i}\right)$ admits a continuous density $f_{i}\left(v_{i}\right)>0$ and has full support. We allow for the possibility that the support of $F_{i}\left(v_{i}\right)$ be the non-negative real line, $[0,+\infty]$. It is assumed that $E\left[v_{i}\right]<\infty$. The assumption that the support of $F_{i}\left(v_{i}\right)$ is bounded below by 0 is not restrictive, since bidders with negative valuations will not enter the auction. The private valuation, $v_{i}$, is only known by bidder $i$, and it is learned before entering the first auction.

The seller wants to allocate $K$ identical units. These units are auctioned off sequentially by the seller using an English (ascending price) auction for every unit. All participating bidders observe the total number of individuals who take part of the auction, $N$. After every auction, each participant observes the price paid by the winner and the winner's identity. The seller continues to run subsequent auctions sequentially until all the units are allocated. We assume that all bidders share the same utility function, $U(\cdot)$. The primitives of the model, $K, N, F_{i}(\cdot), U(\cdot)$, are common knowledge.

The strategy set for every bidder is the vector $S \equiv\left(y_{i}^{k}, b_{i}^{k}\right)_{i=1, \ldots, N}^{k=1, \ldots, K}$, where $y_{i}^{k} \in\{0,1\}$, $y_{i}^{k}=1$ indicates that bidder $i$ participates in the auction for unit $k\left(y_{i}^{k}=0\right.$ if bidder $i$ does not participate in the auction for unit $k$ ), and $b_{i}^{k}$ is the maximum amount that bidder $i$ is willing to pay for unit $k$. Bidders play sequentially, or stage by stage. This means that they choose $s_{i}^{k}=\left(y_{i}^{k}, b_{i}^{k}\right)$ after learning the outcome of the previous $(k-1)$ auctions. Bidders participating in auction $k$ observe the price at which each bidder is no longer active (bids are observable) except for the winning bid. It is important to note that this information transmission is consistent with the auction being an English (or ascending price) auction rather than a second price auction. ${ }^{11}$

The seller allocates the unit to the highest bidder: $x_{j}^{k} \in\{0,1\}$ and $x_{j}^{k}=1$ when $j=$ $\underset{i}{\operatorname{argmax}}\left(b_{i}^{k}\right)$ (and 0 otherwise), at a price equal to the second highest bid: $p^{k}=b_{l}^{k}$, where $l=\underset{i \neq j}{\operatorname{argmax}}\left(b_{i}^{k}\right)$. If only one bidder participates in a specific auction this bidder obtains the object for free. Each object is either allocated to one of the $N$ bidders, or it is lost if none of

\footnotetext{
${ }^{11}$ We model the game as in a button auction. Each bidder is holding a button while the price is continuously rising. A bid for bidder $i$ is the value at which bidder $i$ stop holding the button. When there are only two bidders active (holding the button) and one of them releases the button, the auction ends. The active bidder wins the object and pays the price at which the runner up stopped. See Cassady (1967) and Milgrom and Weber (1982) for details.
} 
the bidders decide to participate in the auction.

Participation decisions in each auction are done simultaneously by all bidders. To take part in auction $k$, bidders incur a participation cost, $c^{k}$, at the beginning of the period. As explained before, if only one bidder participates this bidder obtains the object for free, but he bears the participation cost, $c^{k}$, nonetheless. The process is then repeated in every sequential period. We restrict the analysis to the case where the participation cost is zero for the first unit, $c^{1}=0$, and the remaining costs are constant across auctions: $c^{k}=c>0, \forall k>1 .^{12}$

The assumption $c^{k} \neq 0, \forall k>1$ is not without loss of generality because after the first auction has been resolved information is transmitted before the decision of entering another auction. As we further explain in Subsection C.3 in the Online Appendix, this assumption is consistent with the data in our empirical setting, where we observe no demand for some of the units, even though the reservation price is zero. The interpretation is that, in those situations where no-demand is observed, the value that bidders assign to that unit is smaller than the participation cost, c. (We later use this information in Section E in the Online Appendix to partially identify participation costs; see Subsection C.3 in the Online Appendix for a justification of this assumption in our specific empirical setting.)

\subsection{Two Units}

We first analyze the situation where only two goods are sold, $K=2$. In this case, the marginal utility for the first unit is $M U(1)=(1-\alpha) v_{i}$, while the marginal utility for the second one is $M U(2)=[1-\beta(2-1)] v_{i}=(1-\beta) v_{i}$. Let us normalize the marginal utility of the first unit and define the normalized marginal utility as: $N M U(u)=\frac{M U(u)}{1-\alpha}$.

With this normalization, $N M U(1)=v_{i}$, and $N M U(2)=\left(\frac{1-\beta}{1-\alpha}\right) v_{i}=(1+\rho) v_{i}$, where $\rho \equiv \frac{\alpha-\beta}{1-\alpha}$. This representation allows us to characterize the utility function in a simple way

\footnotetext{
${ }^{12}$ Note that the assumption that $c^{1}=0$ is not restrictive as there are no informational shocks before the decision to enter the first auction. If we consider a case with $c^{1} \neq 0$, and given the equilibrium outcome, we can compute the expected utility for every type. Bidders enter the (first and maybe subsequent) auction if, and only if, the expected utility they obtain from the game is positive. The ex-ante expected utility is continuous and increasing in the agent's type. Therefore, we could perform the analysis considering the distribution:
}

$$
F^{*}\left(w_{i}\right) \equiv F\left(v_{i} \mid E U\left(v_{i}\right) \geq 0\right)
$$


where the interpretation of complementarities or substitutabilities depends on the sign of one parameter, $\rho$. The sign of the complementarity parameter, $\rho$, is ultimately linked to the size of the sunk cost, $\alpha$, relative to the size of the deceasing marginal returns, $\beta$ :

- $\rho>0$ iff $\beta<\alpha$ : When $\rho>0$, we say that goods are complements. The reason is that in this case, the marginal utility for the second unit is greater than the marginal utility for the first unit. This is a situation where the sunk cost is relatively more important than the decreasing returns. In our empirical setting, and for reasons that we explain in Section 3, this is an instance that will be more likely (although not exclusively) to occur in spring/summer.

- $\rho<0$ iff $\beta>\alpha$ : When $\rho<0$, we say that goods are substitutes. In this case, the marginal utility for the second unit is lower than the marginal utility for the first unit. Now the decreasing marginal returns effects is relatively more important than the sunk cost effect. This situation is more likely to manifest in autumn/winter, as we discuss in Section 3.

The following is the utility of bidder $i$ in the English-auction:

$$
U_{i}(\cdot)=\left(x_{i}^{1}+x_{i}^{2}+\rho x_{i}^{1} x_{i}^{2}\right) v_{i}-y_{i}^{2} c
$$

where $v_{i} \sim F_{i}\left[0, W_{i}\right]$ is a scalar (with $W_{i}$ finite or infinite), $c>0$, is a scalar arbitrarily close to zero, and $y_{i}^{k}, x_{i}^{k} \in\{0,1\}$ as defined in Subsection 2.1. As discussed above, after normalizing the marginal utility of the first unit to be equal to $v_{i}$, the marginal utility of the second unit is $(1+\rho) v_{i}$.

We will only consider pure strategy symmetric equilibrium. Cases where $\rho \leq-1$ and $\rho=0$ are close to von der Fehr (1994), in Subsections 3.2 and 3.4, respectively. Uniqueness, however, is not proved by von der Fehr in any of those cases.

In the remainder of the paper we refer to $v_{N: N}$ as the highest realization of the random variable $v_{i}$ among $N$ distributions $F_{i}$ (one draw from each distribution), and $v_{N-1: N}$, as the second highest realization. More generally, $v_{j: N}$ is the $j^{\text {th }}$ order statistic for a sample of size $N$ from the distribution $F_{i}\left(v_{i}\right)$. 
Proposition 1. When $\rho>0$, the unique pure strategy symmetric sequential equilibrium is:

- First auction:

- Participation: Bidder i always participates in the first auction, i.e., $y_{i}^{1}=1$

- Bidding Strategy. We have two cases:

(a) If $(1+\rho) v_{i} \equiv \tilde{v}_{i} \leq c$, then $b_{i}^{1}\left(v_{i}\right)=b^{1}\left(v_{i}\right)=v_{i}$

(b) If $(1+\rho) v_{i} \equiv \tilde{v}_{i}>c$, then $b_{i}^{1}\left(v_{i}\right)=b^{1}\left(v_{i}\right)=(2+\rho) v_{i}-c$

- Second auction:

- Participation. We have two cases:

(a) If $(1+\rho) v_{i} \equiv \tilde{v}_{i} \leq c$, then do not participate in the second auction

(b) If $(1+\rho) v_{i} \equiv \tilde{v}_{i}>c$, then participate in the second auction if, and only if, the bidder won the first auction, i.e.: $y_{i}^{2}=1$ iff $x_{i}^{1}=1$

- Bidding Strategy: If bidder i participates in the second auction $\left(y_{i}^{2}=1\right)$, he will continue bidding until the price reaches his own valuation, i.e.: $b^{2}\left(v_{i}\right)=$ $\left[x_{i}^{1}(1+\rho)+\left(1-x_{i}^{1}\right)\right] v_{i}$

One should note that this equilibrium is also an equilibrium in weakly dominant strategies. Hence, the strategies played by all players in this case are optimal (best responses) for any belief that any player might have about other players' beliefs, or actions, or both.

Note that, in this case, the allocation is efficient, and only one bidder will enter the second auction and pay the cost, $c$. This is the minimum cost we can expect to be paid if we want the object to be allocated. Thus, the mechanism is also efficient in terms of minimizing entry costs.

We proceed now to introduce three propositions that will help us identify the model's primitives. Note that, in this case, we do not need to solve the complete model to obtain the results we will use in the estimation.

Proposition 2. When $\alpha<\beta$, the probability that a bidder different from the winner enters the last auction is decreasing in the participation cost, c. Moreover, this probability goes to 1 when c goes to zero. That is: $\operatorname{Lim}_{c \rightarrow 0}\left\{\operatorname{Pr}\left(y_{i}^{2}=1 \mid x_{j}^{1}=1, i \neq j\right)\right\}=1$.

The intuition is the following. Since $\rho<0$, the winner of the first auction will have a valuation for the second unit lower than his utility for the first unit. Hence, there is a positive 
probability that his utility for the second unit is lower than the utility of other bidders. Thus, other bidders will enter the second auction.

Proposition 3. When goods are substitutes, $-1<\rho<0$, it is a dominant strategy for all bidders to bid their valuations for the last unit in the last auction, conditional on entering the auction.

Since this is the last stage of the game, bidders will behave as in a single-unit auction. Thus, it is a dominant strategy to bid one's own valuation.

Proposition 4. When $\rho=c=0$, it is a weakly dominant strategy for all bidders to enter all auctions and bid their valuations in every auction, that is, $y_{i}^{k}=1$ and $b_{i}^{k}=v_{i}, \forall i, k$.

When $\rho=c=0$ this is indeed the unique equilibrium in weakly dominant strategies, but not the unique Nash equilibrium. Since all the valuations are revealed to all bidders in the first stage, equilibria can be constructed where some players do not enter the second auction, or players enter the second auction and bid below their valuations, provided that the two highest types bidders enter both auctions and bid their valuations in both. Note, however, that in any case the bidder with the highest valuation will win both units and will pay a price equal to the valuation of the bidder with the second highest valuation.

We can construct any such equilibrium by using a parameter $\tau \in(0,2)$, and define the strategies for all players as $y_{i}^{k}=1, b_{i}^{1}=(\tau) v_{i}$ and $b_{i}^{2}=(2-\tau) v_{i}, \forall i, k$. Then, for any $\tau \in(0,2)$ this is an equilibrium. Also, for $\tau \neq 1$ these strategies are not weakly dominant. See, for example, $b_{i}^{2}=(2-\tau) v_{i}$. Since this is the last action of the game, the only weakly dominant strategy is to bid one's valuation: $b_{i}^{2}=v_{i}$. A corollary of Proposition 4 is that, when $\tau=1$, this is indeed an equilibrium in weakly dominant strategies. ${ }^{13}$ These results will also hold when $\rho>0$ and $c=0$. When $\rho<0, c=0$ and $k=2$, the model is identical to Black and De Meza (1992) and the proposition no longer holds. Hence, there is continuity in strategies only when $\rho>0$ and $\rho \rightarrow 0$ (but not when $c>0$ and $c \rightarrow 0$ ).

\footnotetext{
${ }^{13}$ Note that, due to the revelation principle, the revenues for each player will be the same regardless of the equilibrium played.
} 


\subsection{Four Units}

The relevant unit of analysis are four-unit auctions (we provide further details about this in the next section). We present now the following two corollaries that extend the results from the previous subsection to the case where four units are sold, $K=4$ (see Subsection A.2 in the Online Appendix for the details).

We say that goods are pure complements if the marginal utility for the first unit is below the marginal utility for the remaining units $(3 \beta \leq \alpha)$. Goods are non pure complements otherwise $(3 \beta>\alpha)$. The following two corollaries summarize the results we use in the structural estimation:

Corollary 1. When goods are pure complements, $\beta \leq \frac{\alpha}{3}$, the marginal utility of the winner (of all four auctions) satisfies:

$$
\sum_{k=1}^{4} p^{k}=[4-\alpha-6 \beta] v_{N-1: N}-3 c
$$

Corollary 2. When goods are not pure complements, $\beta>\frac{\alpha}{3}$, the marginal utility of the winner in the last auction, depending on how many units the winner won, satisfies:

If the winner won all four units:

$$
p^{4}=(1-\alpha) v_{N-1: N}-c
$$

If the winner won three units, two out of the first three, and the last one:

$$
p^{4}=(1-\beta) v_{N-1: N}-c
$$

\section{Data Description}

In this section we describe the auction allocating system and the data. For our analysis, it is critical to introduce the empirical regularities that support the contention that the size of sunk costs relative to decreasing marginal returns provide the basis for the existence of two regimes and to justify the modeling assumptions made in Section 2 within our empirical context. We perform these tasks in Section $\mathrm{C}$ in the Online Appendix.

The data in this paper come from all water auctions in Mula, Spain, from January 1954 
through August 1966, when the last auction was run. ${ }^{14}$ On August 1st, 1966, the allocation system was modified from being an auction allocation system to a two-sided bargaining system. In the bargaining system, the Heredamiento the Aguas (water-owners holding) and Sindicato de Regantes (land-owners association) arranged a fixed price (renegotiated at the beginning of every six months) for every cuarta of water (the smallest unit auctioned). Gradually, the Sindicato de Regantes bought shares in the Heredamiento the Aguas association until they finally merged in 1974. Thereafter water was allocated to each farmer following a fixed quota, and each piece of land was entitled to some proportion of the water every year.

The reasons for focusing on the period from 1954 to 1966 are, first, that it represents the final period of the auction allocating system that was used for at least eight centuries in this region. Second, given that the government carried out a special agricultural census in $1954 / 55$, we are able to obtain a detailed profile information about the farmers that bid in the auctions for this period.

Apart from being a remarkably stable market institution that had been active since the $13^{\text {th }}$ century, the study of sequential auctions in the present scenario introduces a unique circumstance for analyzing a stark pattern of outcomes not documented in the literature before. Sometimes, winning prices exhibit a standard competitive pattern where, regardless of whether the same or different farmers win the sequential units, prices are similar in magnitude (Figure 1). Other times, one farmer wins all sequential units; he pays a high price for the first unit, deterring other farmers from entering subsequent auctions, thus paying a very low price for the remaining units. We call this the deterrence effect (Figure 2). ${ }^{15}$

The relative importance of sunk costs and decreasing marginal returns cause farmers to coordinate, affecting their marginal utility for subsequent units (within four-unit auctions). This feature must be taken into account if any estimations or inferences are to be accurate. An alternative hypothesis to the behavior of farmers in the case of complementarities, discussed in Subsection 5.4, is that bidders might be playing some collusive (non-competitive) strategy. When the former effect is relatively high (as defined in previous section), the deterrence effect becomes apparent and the price pattern documented in Figure 2 is observed.

\footnotetext{
${ }^{14}$ Data available in the historical archive of Mula go back until 1803.

${ }^{15}$ In terms of purchasing power, one peseta from 1950 is approximately equivalent to 0.43 U.S. dollars from 2013 (for details see footnote 14 in Subsection C.1 in the Online Appendix).
} 


\begin{tabular}{c|l|r|c} 
Auction \# & Name & Price & Day \\
\hline 1 & Pedro Fernández & 123 & \\
2 & Pedro Fernández & 111 & Mo \\
3 & Pedro Fernández & 111 & \\
4 & Pedro Fernández & 109 & \\
\hline 5 & Pedro Blaya & 115 & \\
6 & Jose Ruiz & 116 & Tu \\
7 & Mauricio Gutierrez & 117 & \\
8 & Mauricio Gutierrez & 106 & \\
\hline 9 & Ambrosio Ortiz & 116 & \\
10 & Ambrosio Ortiz & 100 & We \\
11 & Ambrosio Ortiz & 100 & \\
12 & Carlota Pomares & 116 & \\
\hline 13 & Eliseo Gutierrez & 120 & \\
14 & Antonio Muñoz & 112 & Th \\
15 & Antonio Navarro & 110 & \\
16 & Vicente Ledesma & 106 & \\
\hline 17 & Jose Galvez & 103 & \\
18 & Juan Martinez & 91 & \multirow{2}{*}{ Fr } \\
19 & Juan Martinez & 90 & \\
20 & Jesus Gutierrez & 100 &
\end{tabular}

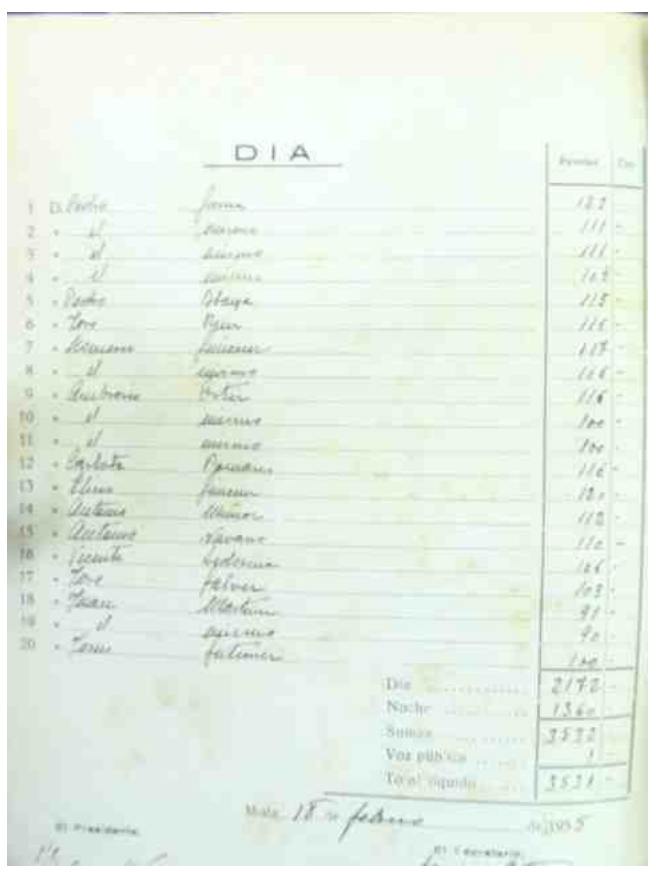

Sample from original data obtained from the historical archive: Goods Are Substitutes (Winter - February 18, 1955, Day). Units 1 to 4 are the units bought on Monday (Mo) during day (unit 1 corresponds to right to irrigate from 7AM to 10AM, unit 2 from $10 \mathrm{AM}$ to $1 \mathrm{PM}$, unit 3 from $1 \mathrm{PM}$ to $4 \mathrm{PM}$, and unit 4 from $4 \mathrm{PM}$ to $7 \mathrm{PM}$ ). Similarly, units 5 to 8 are the units bought on Tuesday ( $\mathrm{Tu}$ ) during day; units 9 to 12 are the units on Wednesday (We) during day; units 13 to 16 are the units on Thursday (Th) during day; and units 17 to 20 are the units on Friday (Fr) during day.

Figure 2: Auction Sample: Goods Are Complements

\begin{tabular}{c|l|r|c} 
Auction \# & Name & Price & Day \\
\hline 1 & Juana Fernández & 1580 & \\
2 & Juana Fernández & 50 & \multirow{2}{*}{ Mo } \\
3 & Juana Fernández & 50 & \\
4 & Juana Fernández & 50 & \\
\hline 5 & Francisco Gabarrón & 1401 & \\
6 & Francisco Gabarrón & 50 & Tu \\
7 & Francisco Gabarrón & 50 & \\
8 & Francisco Gabarrón & 50 & \\
\hline 9 & Jose Fernández & 1401 & \\
10 & Jose Fernández & 25 & We \\
11 & Jose Fernández & 25 & \\
12 & Jose Fernández & 25 & \\
\hline 13 & Antonio Belijar Boluda & 1401 & \\
14 & Antonio Belijar Boluda & 25 & \multirow{2}{*}{ Th } \\
15 & Antonio Belijar Boluda & 25 & \\
16 & Antonio Belijar Boluda & 25 & \\
\hline 17 & Manuel Gutiérrez & 1406 & \\
18 & Manuel Gutiérrez & 50 & \multirow{2}{*}{ Fr } \\
19 & Manuel Gutiérrez & 50 & \\
20 & Manuel Gutiérrez & 50 &
\end{tabular}

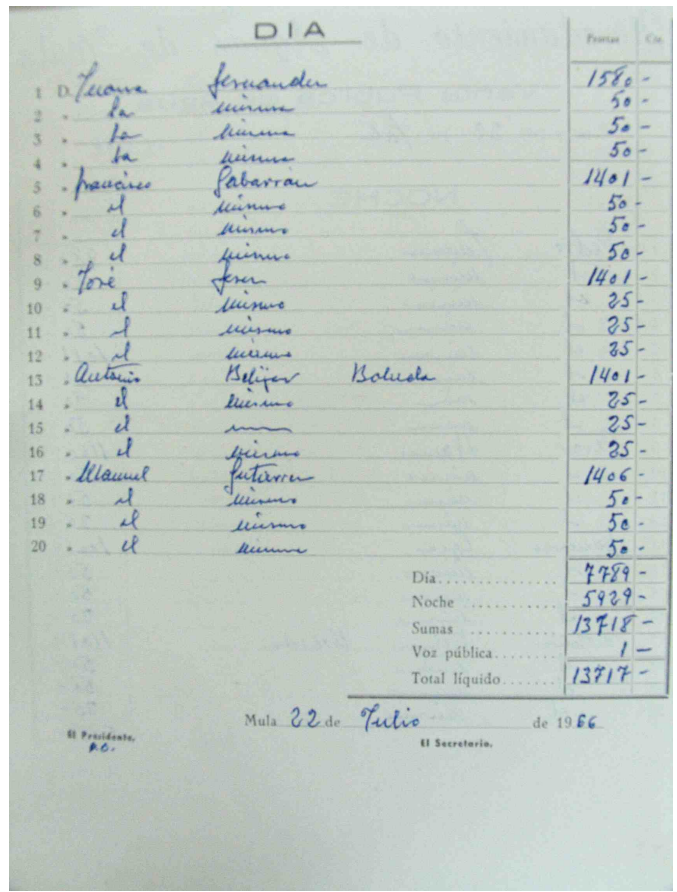

Sample from original data obtained from the historical archive: Goods Are Complements (Summer - July 22, 1966, Day). See notes in Figure 1. 


\subsection{Water Auctions as Allocation System}

Although the process of allocating water in Mula has varied slightly over the years, its basic structure has remained, essentially, unchanged since the $15^{\text {th }}$ century. Land in Mula is divided into regadio (irrigated land) and secano (dry land). Irrigation is only permitted in the former. A channel system allows water from the river to reach all regadio lands. ${ }^{16}$ The fundamental reason for this division is that regadio are fertile lands close to rivers, and thus allow a more efficient use of the scarce water in the region. Since it is forbidden to irrigate lands categorized as secano, only the farmers that own a piece of regadio land in Mula are allowed to buy water.

The mechanism to allocate water to those farmers is a sequential outcry ascending price (or English) auction. The auctioneer sells by auction each of the units sequentially and independently of each other. The auctioneer keeps track of the name of the buyer of every unit and the price paid by the winner. ${ }^{17}$

The basic selling unit is a cuarta (quarter), which is the right to use water that flows through the main channel for three hours. Water storage is done in the De La Cierva dam. Water flows from the dam through the channels at approximately 40 liters per second. As a result, one cuarta carries, approximately, 432,000 liters of water. Traditionally, auctions were made every 21 days to complete a tanda (quota), which is the basic aggregate unit of irrigation time. During our sample period, auctions were carried out once a week on Friday.

In every session, 40 cuartas were auctioned: four cuartas for irrigation during the day (from 7:00 AM to 7:00 PM) and four cuartas for irrigation during the night (from 7:00 PM to 7:00 AM), for each weekday (Monday to Friday). The auctioneer would first sell the 20 cuartas corresponding to the night-time, and then the 20 cuartas corresponding to the daytime. Within each of these groups (day and night), units were sold beginning with Monday

\footnotetext{
${ }^{16}$ The channel system was expanded from the $13^{\text {th }}$ to $15^{\text {th }}$ century, as a response to the greater demand for land due to the increase in population. The regadio land structure has not change since the $15^{\text {th }}$ century.

${ }^{17}$ The farmers could not store water in their plots, and reselling water was forbidden. While a farmer could steal water by opening the gate next to his own parcel, the technology for detection of this crime was effective as irrigation was done by flood irrigation (see Subsection C.3 in the Online Appendix). It was easy to determine who stole water just by identifying a flooded parcel from a farmer who did not buy water in the auction for that specific day-schedule (conditional on rainfall). The Tribunal de los Hombres Buenos (Council of Wise Men), composed by elected members among the farmer community, was responsible to provide justice when conflicts between the farmers arose (mostly, irrigating without the right to do so). We investigate this behavior in Donna and Espin-Sanchez (2013).
} 
(four cuartas), and finishing with Friday's quartas.

\subsection{Sources of Data}

We combine data from different sources for our analysis. Auction data, the primary source of data for this study, are obtained from the historical archive of Mula. ${ }^{18}$ Based on bidding behavior and water availability, auction data can be divided into three categories: (i) Regular periods, where the name of the winner, price paid, date and time of the irrigation for each auction transaction is registered, (ii) No-supply periods, where no auctions are conducted due to water shortage in the river or dam/channels damages (usually because of intense rain), and finally (iii) No-demand periods, where auctions are held but no one bids and the registration auction sheet is blank. As we mentioned above, the sample for this study includes almost 13 years of auction data spanning January 1954 to August 1966. Every week, 40 units (corresponding to 40 cuartas) are sold, with the exceptions being when no auction is run (no-supply) or no bids are observed (no-demand). A total of 17,195 auctions were run during the period under analysis (Table A3 in Subsection C.2 in the Online Appendix).

We supplement auctions data with daily rainfall data for Mula and monthly price indexes for Spain, which we obtain from the Agencia Estatal de Metereología, AEMET (which is the National Meteorological Agency), and the Instituto Nacional de Estadistica de España, INE (which is the National Statistics Institute of Spain), respectively. Mediterranean climate rainfall occurs mainly in spring and autumn. Peak water requirements for the products cultivated in the region are reached in spring and summer, between April and August. We discuss how seasonality affects water demand in our empirical setting in Section $\mathrm{C}$ in the Online Appendix.

We further augment our data with individual characteristics of the farmers' land, which we obtain from the 1954/55 agricultural census. ${ }^{19}$ This census was conducted by the Spanish government to enumerate all cultivated soil, producing crops and agricultural assets available in the country. Individual characteristics for the farmers' land (potential bidders which we

\footnotetext{
${ }^{18}$ From the section Heredamiento de Aguas, boxes No.: HA 167, HA 168, HA 169, and HA 170.

${ }^{19}$ Detailed census data is also obtained from the section Heredamiento de Aguas in the historical archive of Mula, box No. 1,210.
} 


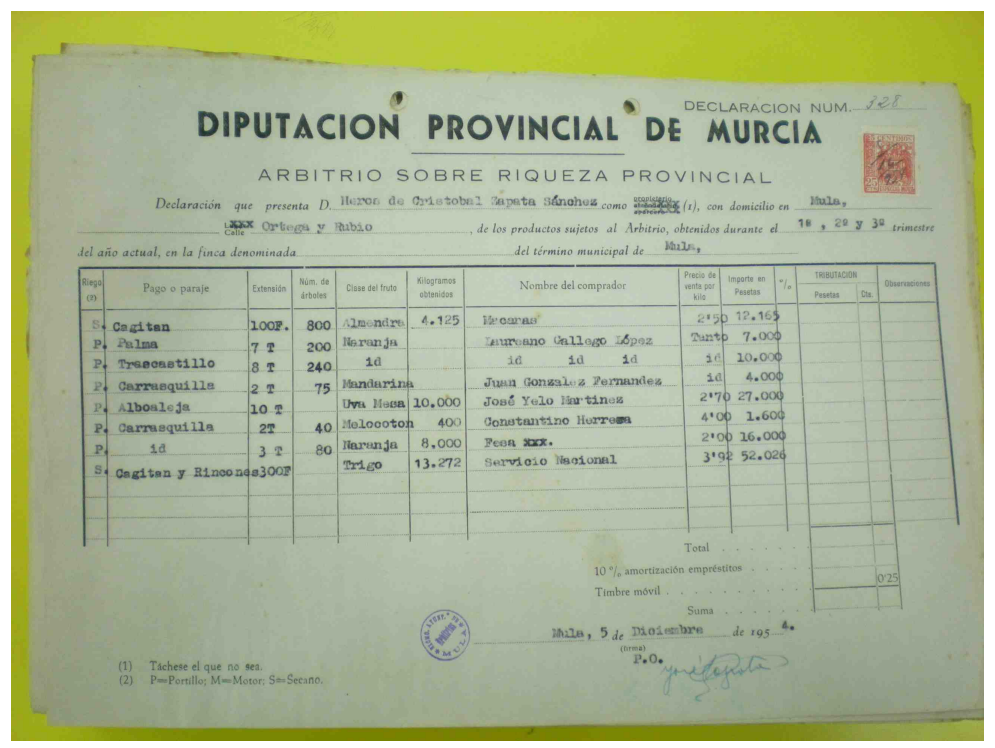

Sample Card from a Farmer Obtained from the Agricultural Census. Individual characteristics include: farmers' name (that we match to the names in the auctions), type of land and location, area, number of trees, production and the price at which this production was sold in the census year.

match with the names in the auctions data) include the type of land and location, area, number of trees, production, and the price at which this production was sold in the census year. Figure 3 shows a sample card for one farmer from the census data. As we discuss in Section 5, during the 13-year period under analysis, there are approximately 500 different bidders in our sample. The number of bidders that win auctions during a specific year is considerably lower - the mean for our sample is around 8 (see table 2 that is discussed in Subsection 5) - and conditional on participating, each farmer wins on average 22 units per year. This is consistent with the census data we have collected, where mean land extension is 5.5 ha. with an average of 33 trees per ha. ${ }^{20}$

In Section B in the Online Appendix we show that regime determination is consistent

\footnotetext{
${ }^{20}$ Average annual rainfall during the period is $320 \mathrm{~mm}$. Recent irrigation studies on young citrus plantings have shown a water use of 2-5 megalitres per hectare annually (Chott and Bradley 1997). Water savings are possible if irrigations can be allocated to similar units of production, such as young trees or reworked sections of a property. In arid regions, like Murcia, water requirements are around $20 \%$ less and they are lower for mature trees. Note that, as discussed in Section C in the Online Appendix, some farmers that are part of water-owner holding use their own water instead of selling it through auctions. Although water stress during droughts affects the quality of production, trees would hardly die as a result. During a normal year without drought, trees could survive the whole year from rainfall alone. For further details see, for example Chott and Bradley (1997), Wright (2000), and du Preez (2001). Finally, note that although the average number of trees per farmer is 161 (see Table A4 in Subsection C.2 in the Online Appendix), the average number of trees per hectare in our sample is 33 (this number is relatively lower than the conventional agricultural standard spacing for citrus trees of 100 trees per hectare).
} 
with end-digit preferences.

We provide a detailed description of the data in Section $\mathrm{C}$ in the Online Appendix: in Subsection C.1 we provide an overview of the industry context, in Subsection C.2 we discuss empirical regularities of the raw data and its summary statistics, and in Subsection C.3 we justify the modeling assumptions made in Section 2 within our empirical context.

\section{Identification}

In this section we discuss identification of the distribution of private valuations and structural parameters conditional on the specific regime being played. The theoretical model in Section 2 along with the procedure described in Section B in the Online Appendix allow us to separate data into four categories:

a) Same bidder wins all four units and goods are pure complements, $\beta \leq \frac{\alpha}{3}$.

b) Same bidder wins all four units and goods are non pure complements, $\beta>\frac{\alpha}{3}$.

c) Last winner also bought two out of the first three units, three units in total, $\beta>\frac{\alpha}{3}$.

d) Otherwise.

According to our model, categories $b, c$, and $d$ are only consistent with a regime where goods are non pure complements.

Our model does not require symmetry in the distribution of private valuations. However, in our empirical application we only observe the identity of the winner who pays the valuation of the runner up (second highest valuation). For the rest of our analysis, we focus in the symmetric case (i.e., $F_{i}=F \forall i$ ). The foundations for identification come from corollaries 1 and 2 (equations 2, 3, and 4). This system provides us with three restrictions in the parameter space.

\section{Parametric Identification}

We now discuss identification by using a specific parametric functional form for the distribution of private valuations. ${ }^{21}$ The question is whether the joint distribution of private

\footnotetext{
${ }^{21}$ Note, however, that for the case of an English auction, the conditional distribution of private valuations is non-parametrically identified when the transaction price and the number of bidders are observable (Athey and Haile 2002).
} 
valuations can be recovered from the distribution of (observed) winning bids alone. The distribution of the $J^{\text {th }}$ order statistic from an i.i.d. sample of size $N$ from an arbitrary distribution $F_{V}($.$) is given by: { }^{22}$

$$
F_{J: N}(x)=\frac{N !}{(N-J) !(J-1) !} \int_{0}^{F_{V}(x)} t^{J-1}(1-t)^{N-J} d t \quad \forall x
$$

Since the right-hand side is strictly increasing in $F_{V}(x)$, for any $J$ and $N$ we can define the function $\phi\left(F_{K: N}(v) ; K, N\right):[0,1] \rightarrow[0,1]$ implicitly by:

$$
F(x)=\frac{N !}{(N-J) !(J-1) !} \int_{0}^{\phi(x)} t^{J-1}(1-t)^{N-J} d t \quad \forall x
$$

This result is immediately useful in our sequential English auction model where bids are conditional-independent draws from a distribution $F_{V}($.$) and the equilibrium (observed)$ transaction price is a function of the second highest valuation, $v_{N-1: N \cdot}{ }^{23}$ Thus, conditional on goods being pure complements, the distribution of valuations is identified up to the multiplying constant using equation 2 and the previous result. To identify the remaining structural parameters, $\alpha$ and $\beta$, we use Corollary 2. Equations 3 to 4 jointly identify the distribution of private values and the structural parameters $\alpha$ and $\beta$.

For our estimation we will allow decreasing marginal returns, $\beta_{t}$, to vary across auctions. Specifically, we are going to model them as a function of farmers' expectations of rain that we are going to proxy by actual (observed) future rain:

$$
\beta_{t}=\beta_{0}+\beta_{1} R_{t}^{F}
$$

where $R_{t}^{F}$ is a dummy variable that is linked to expectations about future rain. $R_{t}^{F}=1$ if farmers expect that rain is going to be positive (for the day for which they are buying water) and zero otherwise. Additionally, we further let $\beta_{t}$ have different intercepts in each regime:

\footnotetext{
${ }^{22}$ Arnold, Balakrishman and Nagaraja (1992) provide an extensive discussion on order statistics, while Athey and Haile (2002) discuss its application for the case of empirical auctions.

${ }^{23}$ Note that this result extends immediately to cases where valuations are affected by auction-specific covariates, $Z_{t}$. In this case, $F_{V}\left(. \mid Z_{t}\right)$ is uniquely identified by $F_{N-1: N}\left(. \mid Z_{t}\right) \forall Z_{t}$ (see Athey and Haile 2002 ).
} 


$$
\begin{aligned}
& \beta_{t}^{S}=\beta_{0}^{S}+\beta_{1}^{S} R_{t}^{F} \\
& \beta_{t}^{C}=\beta_{0}^{C}+\beta_{1}^{C} R_{t}^{F}
\end{aligned}
$$

Table 1 provides an heuristic argument to understand the reasons behind this equation.

Table 1: Rain Expectations and Regime Coordination

\begin{tabular}{lccc}
\hline Variables & $(1)$ & $(2)$ & $(3)$ \\
\hline & & & \\
Future Rain & $-0.0030^{* * *}$ & $-0.0030^{* * *}$ & $-0.0034^{* * *}$ \\
& $(0.0013)$ & $(0.0013)$ & $(0.0013)$ \\
& & & \\
\hline Weekday FE & NO & YES & YES \\
Schedule FE & NO & YES & YES \\
Month FE & NO & NO & YES
\end{tabular}

Sample restricted to the one used in the structural estimation in Table 3. Almost identical results are obtained using the whole sample. All specifications are probit regressions. Marginal effects are reported. Robust standard errors in parenthesis. Dependent variable is a dummy variable equal to one if the regime is pure complements (see Section B in the Online Appendix). Future Rain is a moving average of rain in Mula for seven days after the corresponding date of the auction (Future Rain is a proxy variable for farmers' rain expectations for the day where they are buying water). Past Rain (a moving average of rain in Mula for seven days before the corresponding date of the auction) and Actual Rain (the amount of rain in Mula in the day of the auction) are not statistically significant in any of the above regressions. ${ }^{* * *} \mathrm{p}<0.01,{ }^{* *} \mathrm{p}<0.05$, $* \mathrm{p}<0.1$.

This table presents probit regressions of a dummy variable identifying the regime (pure complements and non pure complements) on future rain and other covariates. As noted above, we interpret future rain in these regressions as a proxy for (aggregate) expected future rain for the farmers. Table 1 shows that low expected rain and high demand months (May to August) significantly increase the likelihood of being in a pure complement regime. The interpretation is that farmers have some information (expectations) about future rain. While the idiosyncratic component of this information is captured by their type, $v_{i}$, the common component is captured by $\beta_{t}$. When farmers expect, on aggregate, no rain in a given day, they will coordinate to play in the pure complements regime. Seasonality also affects the demand for water and affects the position of a farmer in the production curve (Figure 4). The results in Table 1 show that it is the slope on the marginal returns effect that drives the change of regime.

Finally, let $v_{i} \sim F(v ; \mu)$, where $\mu$ is a parameter characterizing the distribution of valuations, $F$. Equations 2, 3, 4, and 6 jointly identify the parameter vector $\left(\mu, \alpha, \beta_{0}^{C}, \beta_{0}^{S}, \beta_{1}^{C}, \beta_{1}^{S}\right)$, 
Figure 4: Marginal Returns of Irrigation Water

SuMmer

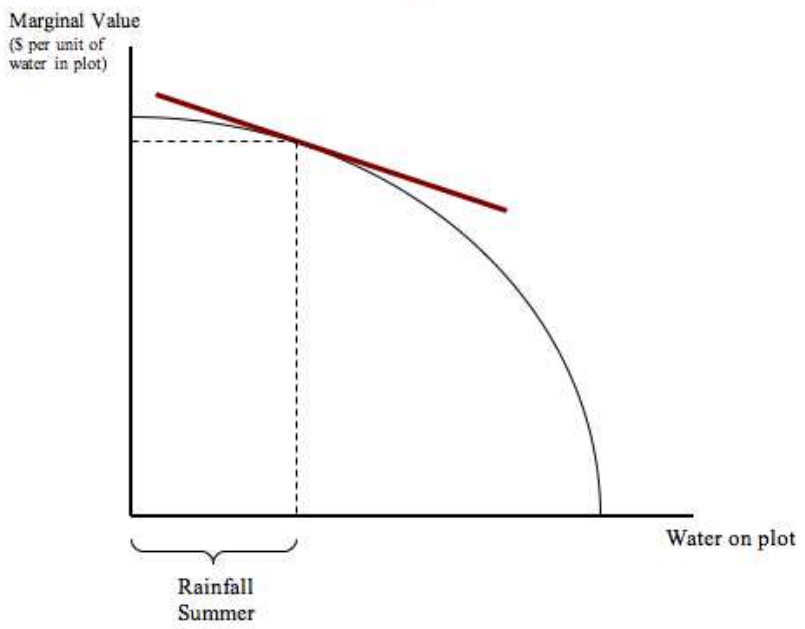

Autumn

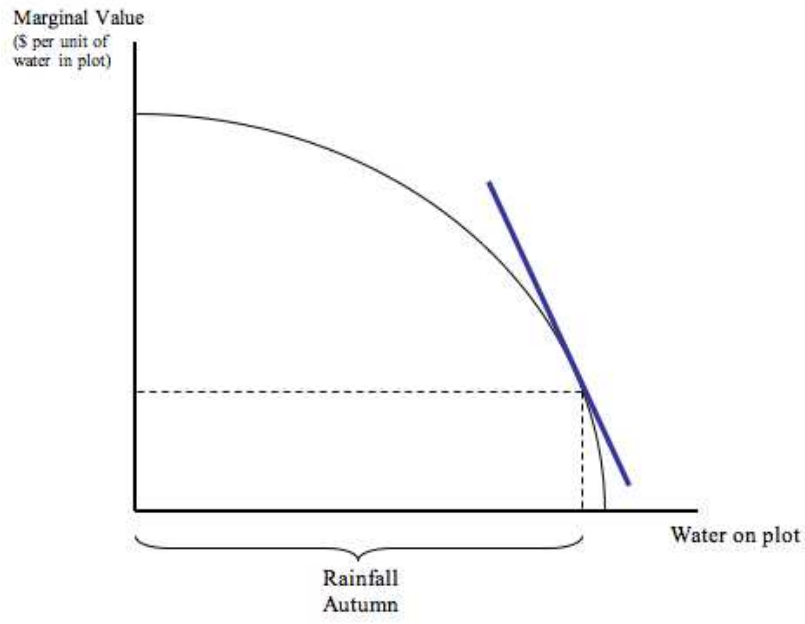

Marginal returns of water in summer (left) and autumn (right).

conditional on regime identification (that we identify non parametrically as described in Section B in the Online Appendix) and exogenous covariates. The full system of equations is given by: $:^{24}$

$$
\begin{gathered}
\sum_{k=1}^{4} p_{a}^{k}=\left[4-\alpha-6 \beta_{t}^{C}\right] v_{N-1: N}-3 c \\
p_{b}^{4}=(1-\alpha) v_{N-1: N}-c \\
p_{c}^{4}=\left(1-\beta_{t}^{S}\right) v_{N-1: N}-c \\
\beta_{t}^{S}=\beta_{0}^{S}+\beta_{1}^{S} R_{t}^{F} \\
\beta_{t}^{C}=\beta_{0}^{C}+\beta_{1}^{C} R_{t}^{F}
\end{gathered}
$$

Finally, note that in our parameterization we fix $\alpha$ across auctions (and seasons) but we allow $\beta_{t}$ to vary. This is necessary to identify them separately but, ultimately (and as evident in the sequential auction model), it is the relative magnitude of the effects that matters. The rationale for why we let $\beta_{t}$ vary (instead of $\alpha$ ) is that a regime switch is driven by the (residual) demand for water by the farmers, as determined by rain and seasonal effects. We expect $\alpha$ to vary across auctions and seasons as well. Given that this variation is not

\footnotetext{
24 The third equation in the system is, actually, $p_{b}^{4}=\operatorname{Max}\left\{(1-\alpha) v_{N-1: N},(1-\beta) v_{N-2: N}\right\}$, since we do not know whether the runner-up in the last auction was the bidder who already won one unit or a bidder without previous purchases. However, when $N$ is large, $(1-\alpha) v_{N-1: N}<(1-\beta) v_{N-2: N}$ if $\beta \simeq \alpha$. But, in the case that $\beta \simeq \alpha$, the same bidder will not win three out of four units. That is, in an auction where $N$ is large and the same bidder wins three out of four units, we expect $\beta$ to be significantly greater than $\alpha$. Therefore, the equation can be simplified to $p_{b}^{4}=(1-\alpha) v_{N-1: N}$.
} 
separately identified from the variation on $\beta_{t}$, we should interpret the estimated changes in $\beta_{t}$ as relative changes with respect to $\alpha$.

We discuss identification and estimation of participation costs in Section E in the Online Appendix.

\section{Estimation}

In this section we discuss the estimation procedure with homogeneous bidders and how we handle the difficulties that arise from it.

The econometric problem consists of finding the common distribution of valuations $F$ and structural parameters that best rationalize the bidding data. As discussed in the previous section, the bid levels at which bidders drop out of the auctions are not observed, except the bidder with the second-highest valuation.

A second concern arises from the likely heterogeneity across auctions. Observed heterogeneity arises due to seasonal effects, rain, and the day and time of the week when the auction occurs. This means that the distribution of private values for the $t^{\text {th }}$ auction, $F_{t}(\cdot)$, is not constant across auctions. In our estimation we recover the family of distributions $F\left(\cdot \mid Z_{t}, \gamma\right)$. That is, we assume for every four-unit auction that $F_{t}(\cdot)=F\left(\cdot \mid Z_{t}, \gamma\right)$, where $\gamma \in R^{k}$ is a parameter vector and $Z_{t}$ is a vector of fully observed characteristics describing the environment of the $t^{t h}$ auction. We describe the inclusion of these covariates in next subsection.

The number of potential bidders in each auction, $N_{t}$, is not observed. Moreover, it is not identified (Athey and Haile 2002). We assume that it is constant for every four-unit auction, $N_{t}=N$. Table 2 displays the timing structure for different bidders in our sample. For our estimation, we let the number of potential bidders in each auction be the yearly average of different farmers that win auctions in our sample. ${ }^{25}$ We estimate the model using different values of $N$ for robustness. ${ }^{26}$

\footnotetext{
${ }^{25}$ The agricultural products that are cultivated in the area are mainly citrus trees, which are harvested once per year. The number of different bidders who bought at least one unit during a specific year constitutes a good approximation to the number of farmers that were actively bidding in each four-unit auction during that year (see Section C in the Online Appendix for further details). The monthly average of different bidders who bought water in the sample (years 1954 to 1966) is 8.31 (Table 2).

${ }^{26}$ In Table 3 we present the results for $N \in\{8,10\}$. We have performed a sensitivity analysis to different values of $N_{t}$ that are consistent with the pattern observed in Table 2 and the evidence described in Section $\mathrm{C}$ in the Online Appendix. In addition, we have performed the estimation by breaking the sample into four
} 
Table 2: Timing Structure of Different Winners: Estimation Sample

\begin{tabular}{c|ccccccccccccc|c} 
Month & 1954 & 1955 & 1956 & 1957 & 1958 & 1959 & 1960 & 1961 & 1962 & 1963 & 1964 & 1965 & 1966 & Total \\
\hline 1 & 4 & 6 & 0 & 3 & 1 & 11 & 3 & 0 & 0 & 0 & 28 & 0 & 11 & 61 \\
2 & 4 & 4 & 0 & 2 & 4 & 2 & 3 & 0 & 0 & 0 & 19 & 0 & 21 & 57 \\
3 & 5 & 3 & 0 & 9 & 0 & 1 & 2 & 0 & 0 & 10 & 29 & 8 & 23 & 79 \\
4 & 0 & 2 & 0 & 6 & 2 & 5 & 4 & 6 & 0 & 17 & 28 & 38 & 28 & 121 \\
5 & 5 & 7 & 0 & 6 & 1 & 13 & 9 & 6 & 9 & 4 & 32 & 30 & 31 & 130 \\
6 & 3 & 7 & 0 & 7 & 0 & 8 & 10 & 7 & 10 & 14 & 23 & 25 & 29 & 119 \\
7 & 2 & 3 & 0 & 6 & 9 & 26 & 8 & 5 & 13 & 15 & 17 & 21 & 23 & 117 \\
8 & 9 & 3 & 0 & 3 & 4 & 10 & 7 & 14 & 18 & 15 & 21 & 16 & 3 & 102 \\
9 & 8 & 8 & 0 & 3 & 8 & 10 & 5 & 13 & 0 & 8 & 35 & 19 & 0 & 97 \\
10 & 8 & 7 & 3 & 2 & 11 & 2 & 0 & 9 & 0 & 10 & 16 & 19 & 0 & 78 \\
11 & 7 & 2 & 3 & 0 & 8 & 2 & 0 & 4 & 0 & 21 & 29 & 23 & 0 & 82 \\
12 & 1 & 0 & 2 & 2 & 3 & 1 & 0 & 0 & 0 & 36 & 18 & 12 & 0 & 69 \\
\hline Total & 48 & 43 & 8 & 43 & 48 & 80 & 47 & 54 & 44 & 106 & 179 & 147 & 128 & 537
\end{tabular}

Total, in the last row, refers to the total number of different winners for the specific year (column). Given that, within a year, the same bidders win multiple units in several months, this number is below the sum over months, by year. Similarly for the last column, where Total is the number of different bidders for the specific month (row) during the 13-year sample. Finally, 537, refers to the total number of different bidders in the whole sample. The monthly average of different bidders who bought water in the sample (years 1954 to 1966$)$ is 8.31 .

An additional concern that, ultimately, maintains an important relation with the empirical setting is that the econometrician may be less informed than the bidders. Throughout, we have assumed that the vector $Z_{t}$ of covariates is fully observed by the econometrician. In our environment, unobserved heterogeneity implies that the distribution of bids may not be conditional-independent across $t$. All farmers may, for example, observe some factor (unobservable by the researcher) that shifts the location of the distribution values. This unobserved heterogeneity could lead to correlation among bidders' valuations, causing an identification problem and inconsistent estimates to arise. ${ }^{27}$ Modeling unobserved heterogeneity may require additional assumptions on the behavior of unobservables (independence, separability, strict monotonicity) and is outside the scope of this paper. ${ }^{28}$

Finally, it is important to understand what is the meaning of $v_{i}$ in a dynamic model.

periods and performing the estimation independently in each period allowing the mean value of $N_{t}$ to vary by period. We obtained similar results to the ones reported in Table 3.

${ }^{27}$ From the agricultural census data we observe individual characteristics of the farmers which we are able to link to the winning bids. Given the structure of the agricultural water market we are modeling, it does not appear to be an important concern once we consider the homogeneity of the selling good and the observed characteristics we introduce in our estimations (seasonality, past and future rain, among others).

${ }^{28}$ For a discussion on this issue see, among others, Athey, Levin and Seira (2011) for an application to timber auctions, and Krasnokutskaya (2011) for a semi-parametric approach to Michigan highway procurement contracts. In a recent investigation, Roberts (2009) uses information contained in reserve prices to allow bidders' private signals to depend on the realization of the unobserved heterogeneity. 
When modeling a single-unit auction, we normalize, by simplicity, the outside option to zero. That is, the interpretation of $v_{i}$ is not the value that the bidder assigns to the object but the difference between the value that the bidder assigns to the object and the value of not having the object (the option value). In the single-unit case, these two definitions coincide, but not in a dynamic setting. In our case, the option value of not winning the first (out of ten, fourunits) auction (say, Monday-Night) is positive, since there are many options to buy water before the end of the process. However, the value of not winning the last auction (say, FridayDay) is zero, since this is the last auction until next week. Hence, what the econometrician is estimating in a sequential auction setting is the difference between the utility of the bidder when he wins the object and when he does not. This difference is changing as the auction process evolves. We are aware that this effect is present, and we capture it by including dummy variables for the 10 (four-units) different auctions.

These dummy variables account for this option value effect. Although the dummy variable capture a linear effect, the option value need not be linear. We analyze this by checking for correlation and auto-correlation between the errors within and between four-units auctions. We find no significant correlation. We interpret this in favor of the assumption of conditionalindependence between four-units auctions.

Unlike in Donald and Paarsch (1993) and Laffont, Ossard and Vuong (1995), the support of the distribution of the winning bid as defined in the previous section does not depend on the parameter vector. Maximum Likelihood Estimation (MLE) is possible in our setting where losing bids are not observed. ${ }^{29}$ Let $\theta \equiv\left(\alpha, \beta_{0}^{C}, \beta_{0}^{S}, \beta_{1}^{C}, \beta_{1}^{S}\right)$ and let $v_{i}$ be a conditional-independent draw from a parametric distribution (known by the econometrician) $F\left(\cdot ; \mu \mid \theta, Z_{t}, \gamma\right)$ where $\mu \in \Theta^{l}$ is the parameter of a family of distributions. Then, the likelihood function is given by:

\footnotetext{
${ }^{29}$ Another potential concern with the likelihood approach in this context is the assumption that the winning bid equals the second highest valuation (after considering sunk cost and decreasing marginal returns effects). This assumption is likely to be violated when bids rise in discrete steps, and especially in cases where bids increase faster than the required minimum (that is, jumping bidding). This is not the case in our setting. Winner prices exhibit great variation (see summary statistics in Tables A4 and A5 in Subsection C.2 in the Online Appendix) and cents bids are frequently observed.
} 


$$
\begin{aligned}
L\left(\mu, \theta, \gamma \mid p_{t}^{i}, R_{t}^{F}, Z_{t},\left\{D_{t}^{j}\right\}_{j \in\{a, b, c\}}, N\right)= & \prod_{t=1}^{T} f_{N-1: N}\left(\frac{\sum_{k=1}^{4} p_{t}^{k}}{4-\alpha-6\left(\beta_{0}^{C}+\beta_{1}^{C} R_{t}^{F}\right)} ; \mu \mid \theta, \gamma, R_{t}^{F}, Z_{t},\left\{D_{t}^{j}\right\}_{j \in\{a, b, c\}}, N\right)^{D_{t}^{a}} \mathbf{x} \\
& f_{N-1: N}\left(\frac{p_{t}^{4}}{1-\alpha} ; \mu \mid \theta, \gamma, R_{t}^{F}, Z_{t},\left\{D_{t}^{j}\right\}_{j \in\{a, b, c\}}, N\right)^{D_{t}^{b}} \mathbf{x} \\
& f_{N-1: N}\left(\frac{p_{t}^{4}}{1-\beta_{0}^{S}+\beta_{S}^{C} R_{t}^{F}} ; \mu \mid \theta, \gamma, R_{t}^{F}, Z_{t},\left\{D_{t}^{j}\right\}_{j \in\{a, b, c\}}, N\right)^{D_{t}^{c}}
\end{aligned}
$$

where $f_{N-1: N}(v ; \mu)$ is the probability density function $(\mathrm{PDF})$ of the $(N-1)^{t h}$ order statistic from a sample of $N$ from the distribution of valuations $F, D_{t}^{a}+D_{t}^{b}+D_{t}^{c}=1 \forall t$, and $D_{t}^{a}$, $D_{t}^{b}, D_{t}^{c}$ are, respectively, indicator variables for cases $a, b$, and $c$, outlined in Section 4 .

\subsection{Distribution of Private Values}

Our model and the context of the market under analysis provide insight on how the characteristics of farmers and auctions should affect private values, but it offers little guidance on the functional form of this distribution. We assume that farmers' valuations, $v_{i}$, follow an an exponential distribution for each four-unit auction. ${ }^{30,}{ }^{31}$ In Subsection 5.2 we report the results from a Kolmogorov-Smirnov test where the null hypothesis that the distribution of private valuations are draws from an exponential distribution cannot be rejected.

To recover both, the structural parameters and the distribution of values conditional on the vector of covariates, we let the mean of the distribution of valuations depend on various characteristics that are drawn from our data. We assume that observed prices follow a linear function of the following exogenous variables and estimate all parameters using the likelihood function: ${ }^{32}$

\footnotetext{
${ }^{30}$ Following our notation above, the CDF is given by $F(v ; \mu)=\left(1-e^{-\mu v}\right) \mathbf{1}\{v \geq 0\}$ and is completely characterized by the scalar $\mu>0$.

${ }^{31}$ In our earlier working paper Donna and Espin-Sanchez 2012 we used an Exponentiated Gamma (EG) distribution The EG distribution gives us a closed-form solution for the PDF of the $j^{\text {th }}$ order statistic and it is characterized by a single parameter; additionally, the PDF of the $j^{\text {th }}$ order statistic of a EG is a weighted average of several PDF of EG. This implies that the PDF of any order statistic of an EG distribution also has a closed-form solution.

${ }^{32}$ Laffont, Ossard and Vuong (1995) assume that private values follow a log-normal distribution and let the mean of the logarithm of the valuations be a linear function of exogenous characteristics. Haile and Tamer (2003) condition on covariates by constructing the conditional empirical distribution functions using Gaussian kernels. See Hickman, Hubbard and Saglam (2011) for a recent guide to the literature on structural econometric methods in auctions.
} 


$$
\mathbb{E}\left(v_{t}^{i}\right)=Z_{t}^{\prime} \gamma=\gamma_{0}+\gamma_{1} R_{t}^{P}+\gamma_{2}\left(R_{t}^{P}\right)^{2}+\gamma_{3} N i g h t_{t}+\sum_{k=2}^{5} \gamma_{2+i} \text { Day }_{t}^{k}+\sum_{k=2}^{12} \gamma_{6+i} \text { Mont }_{t}^{k}
$$

The first exogenous variable, $R_{t}^{P}$, refers to Past Rain, a moving average of the daily rain beginning seven days prior to the date of the auction; we include a quadratic term to allow for non linearities in past rain. The second variable is a dummy variable that equals one if the water was bought for night use. The next four variables are a set of dummy variables for each weekday. Finally, the last eleven variables are a complete set of monthly dummy variables to condition on seasonality. Water prices soar in this market during the dry summer and drop in winter. We accommodate these shocks to demand with seasonal monthly dummy variables. See Sections D and E in the Online Appendix for details about the estimation procedure.

\subsection{Estimation Results}

In this section we present the estimation results of the structural model associated with the theoretical benchmark of Section 2 under various econometrics specifications. We present the structural estimates obtained using a tolerance level of $1.0 e-25$. We let private valuations for each four-unit auction follow an exponential distribution, and follow the described estimation procedure. As discussed above, the number of bidders, $N$, is determined by the monthly average of different bidders who bought water in the sample (years 1954 to 1966). In this 13year sample, the average is slightly above 8. Each of these farmers regularly won auctions. It is reasonable to assume that they attended the auctions. ${ }^{33}$ Tables 3 and 4 present our estimation results. Columns 1, 3, and 5 present the estimates for $N=8$, while columns 2, 4, and 6 do it for $N=10 .^{34}$

\footnotetext{
${ }^{33}$ See Section C in the Online Appendix for further details.

${ }^{34}$ In their simulated NLLS estimation, Laffont, Ossard and Vuong (1995) search for the best value of $N$ by minimizing a lack-of-fit criterion (proposition 4). Note that, as discussed in Subsection 4, identification of the distribution of valuations and structural parameters of our model requires observation of the total number of bidders. The rationale for this is straightforward: whether second highest realization of the random variable $v_{i}$ is from a sample of size $N=10$, or from a sample of size $N=100$, is crucial to interpret the second highest bid (observable in our data). Although observation of an additional order statistic can eliminate this
} 
Table 3: Structural Estimation

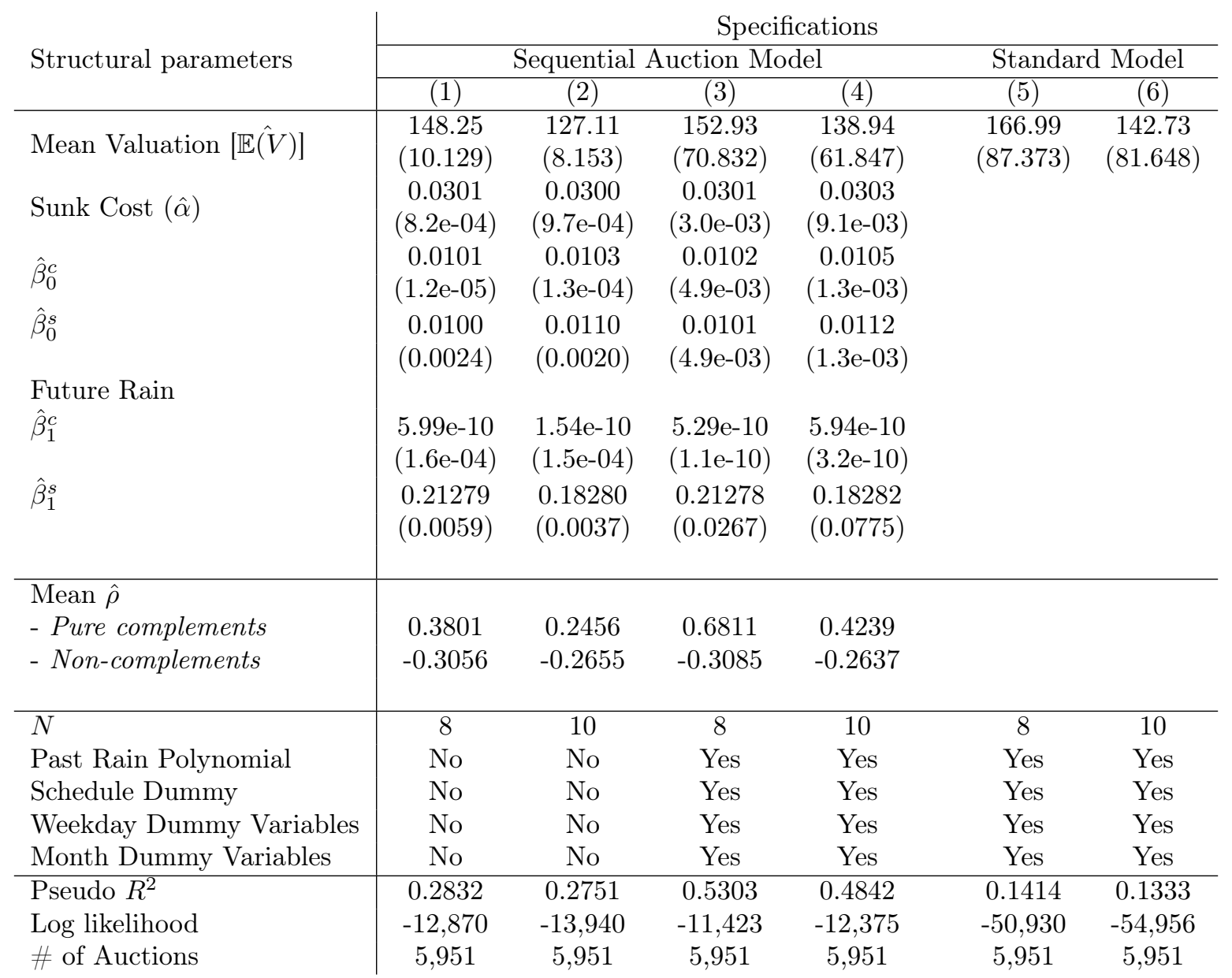

Bootstrapped standard errors $(B=1,000)$ are reported in parenthesis (for the Mean Valuation it corresponds to the bootstrapped standard error corresponding to $Z_{t}^{\prime} \gamma$ ). Estimates in columns 1 to 4 (sequential auction model) are obtained using the estimation procedure described in Section 5 using KNITRO, a solver for nonlinear optimization, with tolerance level of 1.0e-25 (see Sections D and E in the Online Appendix for details). For the distribution of private values and inclusion of covariates, we use the parametric specification described in Subsection 5.1. Estimates in specifications 5 and 6 (standard model) are MLE obtained by maximizing the likelihood function from a standard English auction model allowing the mean of the distribution of valuations depend on the same characteristics as in the other specifications as indicated in equation 9, without fixed costs nor decreasing marginal returns (the sample is the same as the one in columns 1 to 4 , including in this case all sequential prices in the estimation). Although not reported in the table, the coefficients form an OLS regression of the residuals from the model in specification 3 against the covariates in that specification are not statistically different from zero. Number of years in the sample is 13 . Number of months in the sample is 119. The number of different winners (across all 13 years) is 537. The complementarity parameter, $\rho$, is computed as detailed in the theoretical model in Section 2. When the goods are pure complements is given by $\rho_{t}^{C}=\frac{\alpha-3 \beta_{t}^{C}}{1-\alpha}=\frac{\alpha-3\left(\beta_{0}^{C}+\beta_{1}^{C} R_{t}^{F}\right)}{1-\alpha}$. The table reports, for each specification of the sequential auction model in columns 1 to $4: \hat{\bar{\rho}}^{C}=\frac{\hat{\alpha}-3\left(\hat{\beta_{0}^{C}}+\hat{\beta}_{1}^{C} \frac{1}{T}\left(\sum_{t=1}^{T} D_{a, t} R_{t}^{F}\right)\right)}{1-\hat{\alpha}}$. Similarly, when the goods are non-complements, the table reports, for each specification: $\hat{\bar{\rho}}^{S}=\frac{\hat{\alpha}-3\left(\hat{\beta}_{0}^{S}+\hat{\beta}_{1}^{S} \frac{1}{T}\left(\sum_{t=1}^{T}\left(D_{b, t} R_{t}^{F}+D_{c, t} R_{t}^{F}\right)\right)\right)}{1-\hat{\alpha}}$. 
Table 4: Structural Estimation (continued)

\begin{tabular}{|c|c|c|c|c|c|c|}
\hline \multirow{3}{*}{ Structural parameters } & \multicolumn{6}{|c|}{ Specifications } \\
\hline & \multicolumn{4}{|c|}{ Sequential Auction Model } & \multicolumn{2}{|c|}{ Standard Model } \\
\hline & (1) & $(2)$ & (3) & (4) & $(5)$ & $(6)$ \\
\hline Covariates & & & & & & \\
\hline Past Rain $\left(\hat{\gamma}_{1}\right)$ & & & $\begin{array}{l}-1.668 \\
(0.301)\end{array}$ & $\begin{array}{l}-2.076 \\
(0.547)\end{array}$ & $\begin{array}{l}-1.416 \\
(0.379)\end{array}$ & $\begin{array}{c}-1.2422 \\
(0.664)\end{array}$ \\
\hline$(\text { Past Rain })^{2}\left(\hat{\gamma}_{2}\right)$ & & & $\begin{array}{c}0.0076 \\
(0.0448)\end{array}$ & $\begin{array}{c}0.0126 \\
(0.0958)\end{array}$ & $\begin{array}{c}0.0034 \\
(0.1496)\end{array}$ & $\begin{array}{c}0.0032 \\
(0.1520)\end{array}$ \\
\hline Night $\left(\hat{\gamma}_{3}\right)$ & & & $\begin{array}{c}-27.230 \\
(7.556)\end{array}$ & $\begin{array}{l}-23.56 \\
(9.649)\end{array}$ & $\begin{array}{c}-30.003 \\
(5.039)\end{array}$ & $\begin{array}{c}-25.916 \\
(3.629)\end{array}$ \\
\hline Tuesday $\left(\hat{\gamma}_{4}\right)$ & & & $\begin{array}{c}-0.2873 \\
(0.6449)\end{array}$ & $\begin{array}{l}-10.985 \\
(9.7063)\end{array}$ & $\begin{array}{c}-2.7134 \\
(7.1630)\end{array}$ & $\begin{array}{l}-2.4331 \\
(2.6197)\end{array}$ \\
\hline Wednesday $\left(\hat{\gamma}_{5}\right)$ & & & $\begin{array}{c}-2.4616 \\
(0.5406)\end{array}$ & $\begin{array}{c}-2.1883 \\
(0.9572)\end{array}$ & $\begin{array}{l}-5.8751 \\
(2.5602)\end{array}$ & $\begin{array}{c}-5.0944 \\
(6.0395)\end{array}$ \\
\hline Thursday $\left(\hat{\gamma}_{6}\right)$ & & & $\begin{array}{c}-8.8423 \\
(0.6169)\end{array}$ & $\begin{array}{c}-8.366 \\
(0.8544)\end{array}$ & $\begin{array}{l}-15.755 \\
(4.7014)\end{array}$ & $\begin{array}{c}-13.502 \\
(2.5863)\end{array}$ \\
\hline Friday $\left(\hat{\gamma}_{7}\right)$ & & & $\begin{array}{c}-17.805 \\
(5.016)\end{array}$ & $\begin{array}{l}-9.795 \\
(3.418)\end{array}$ & $\begin{array}{c}-28.154 \\
(12.903)\end{array}$ & $\begin{array}{c}-24.271 \\
(2.118)\end{array}$ \\
\hline Feb $\left(\hat{\gamma}_{8}\right)$ & & & $\begin{array}{c}-11.373 \\
(23.299)\end{array}$ & $\begin{array}{l}-41.023 \\
(35.705)\end{array}$ & $\begin{array}{l}-4.8293 \\
(2.330)\end{array}$ & $\begin{array}{c}-5.0584 \\
(4.949)\end{array}$ \\
\hline $\operatorname{Mar}\left(\hat{\gamma}_{9}\right)$ & & & $\begin{array}{c}27.356 \\
(12.386)\end{array}$ & $\begin{array}{l}18.067 \\
(8.491)\end{array}$ & $\begin{array}{l}34.954 \\
(5.218)\end{array}$ & $\begin{array}{l}30.126 \\
(1.676)\end{array}$ \\
\hline $\operatorname{Apr}\left(\hat{\gamma}_{8}\right)$ & & & $\begin{array}{c}82.481 \\
(23.456)\end{array}$ & $\begin{array}{c}53.902 \\
(17.127)\end{array}$ & $\begin{array}{l}78.799 \\
(3.426)\end{array}$ & $\begin{array}{c}67.396 \\
(11.579)\end{array}$ \\
\hline May $\left(\hat{\gamma}_{10}\right)$ & & & $\begin{array}{l}115.140 \\
(24.822)\end{array}$ & $\begin{array}{c}81.751 \\
(30.187)\end{array}$ & $\begin{array}{l}114.483 \\
(4.366)\end{array}$ & $\begin{array}{c}96.142 \\
(15.015)\end{array}$ \\
\hline $\operatorname{Jun}\left(\hat{\gamma}_{11}\right)$ & & & $\begin{array}{c}49.771 \\
(23.112)\end{array}$ & $\begin{array}{c}40.248 \\
(18.698)\end{array}$ & $\begin{array}{l}57.478 \\
(8.429)\end{array}$ & $\begin{array}{l}48.341 \\
(15.16)\end{array}$ \\
\hline $\operatorname{Jul}\left(\hat{\gamma}_{12}\right)$ & & & $\begin{array}{l}195.980 \\
(26.035)\end{array}$ & $\begin{array}{l}115.752 \\
(48.982)\end{array}$ & $\begin{array}{c}225.337 \\
(216.025)\end{array}$ & $\begin{array}{c}191.341 \\
(102.962)\end{array}$ \\
\hline $\operatorname{Aug}\left(\hat{\gamma}_{13}\right)$ & & & $\begin{array}{l}233.750 \\
(28.562)\end{array}$ & $\begin{array}{c}183.06 \\
(27.608)\end{array}$ & $\begin{array}{c}247.57 \\
(195.347)\end{array}$ & $\begin{array}{c}210.08 \\
(87.953)\end{array}$ \\
\hline $\operatorname{Sep}\left(\hat{\gamma}_{14}\right)$ & & & $\begin{array}{c}74.494 \\
(23.684)\end{array}$ & $\begin{array}{c}160.78 \\
(34.040)\end{array}$ & $\begin{array}{c}88.173 \\
(39.318)\end{array}$ & $\begin{array}{c}74.259 \\
(12.133)\end{array}$ \\
\hline $\operatorname{Oct}\left(\hat{\gamma}_{15}\right)$ & & & $\begin{array}{c}77.623 \\
(14.532)\end{array}$ & $\begin{array}{c}62.664 \\
(22.385)\end{array}$ & $\begin{array}{c}81.093 \\
(30.165)\end{array}$ & $\begin{array}{c}69.953 \\
(10.558)\end{array}$ \\
\hline $\operatorname{Nov}\left(\hat{\gamma}_{16}\right)$ & & & $\begin{array}{c}3.3622 \\
(2.3941)\end{array}$ & $\begin{array}{r}-13.302 \\
(7.513)\end{array}$ & $\begin{array}{l}13.2099 \\
(16.725)\end{array}$ & $\begin{array}{l}10.6131 \\
(9.6974)\end{array}$ \\
\hline $\operatorname{Dec}\left(\hat{\gamma}_{17}\right)$ & & & $\begin{array}{c}7.4696 \\
(2.2226)\end{array}$ & $\begin{array}{l}-0.9495 \\
(2.5513)\end{array}$ & $\begin{array}{c}2.8462 \\
(3.6735)\end{array}$ & $\begin{array}{c}2.2106 \\
(4.0308)\end{array}$ \\
\hline Intercept $\left(\hat{\gamma}_{0}\right)$ & $\begin{array}{c}148.253 \\
(10.121)\end{array}$ & $\begin{array}{l}127.117 \\
(8.153)\end{array}$ & $\begin{array}{c}90.885 \\
(32.274)\end{array}$ & $\begin{array}{c}96.131 \\
(25.754)\end{array}$ & $\begin{array}{c}101.717 \\
(179.285)\end{array}$ & $\begin{array}{c}87.978 \\
(74.073)\end{array}$ \\
\hline$N$ & 8 & 10 & 8 & 10 & 8 & 10 \\
\hline Pseudo $R^{2}$ & 0.2832 & 0.2751 & 0.5303 & 0.4842 & 0.1414 & 0.1333 \\
\hline Log likelihood & $-12,870$ & $-13,940$ & $-11,423$ & $-12,375$ & $-50,930$ & $-54,956$ \\
\hline \# of Auctions & 5,951 & 5,951 & 5,951 & 5,951 & 5,951 & 5,951 \\
\hline
\end{tabular}

See notes in Table 3. 
For each specification, we present the estimates of the model's structural parameters in Table 3 and the estimates of the covariates in Table 4. Table 4 is the continuation of Table 3. That is, for each specification (column) in Table 3, Table 4 displays the estimates of the covariates in that specification.

All parameters have the expected signs. We use the estimate of the parameter $\gamma$ (that characterizes the distribution of private valuations), to compute the mean valuation of the first complete unit of water. In the case of column 3 , the value of the first complete unit of water is 152.93 pesetas. As expected, in the specification in column 4 (with 10 different bidders), the mean value of the first complete unit of water is slightly lower, 138.9 pesetas.

The parameter $\beta_{1}^{R}, R \in\{C, S\}$ captures the effect of future rain. As farmers' expectations of future rain increase, decreasing marginal returns (DMR) are more severe $\left(\beta_{1}^{R}>0, R \in\right.$ $\{C, S\}$ ). This increases the likelihood of coordinating in a non pure complements regime (see Table 1) and thus reduces their valuation of subsequent units of water $\left(\frac{\partial p_{t}^{i}}{\partial R_{t}^{F}}<0\right)$. Predicted DMR are obtained by adding the estimates of intercepts $\hat{\beta}_{0}^{R}, R \in\{C, S\}$ to that of $\hat{\beta}_{1}^{R}$, $R \in\{C, S\}$, conditional on the rain in the day of the auction.

When evaluated at the average future rain from each regime, the null hypothesis that overall DMR are lower in the pure complements regime cannot be rejected ( $p$-value above $10 \%)$ :

$$
H_{0}: \hat{\beta}_{0}^{S}+\hat{\beta}_{1}^{S} \hat{\mathbb{E}}_{s}\left(R_{t}^{F}\right)>\hat{\beta}_{0}^{C}+\hat{\beta}_{1}^{C} \hat{\mathbb{E}}_{c}\left(R_{t}^{F}\right)
$$

where $\hat{\mathbb{E}}_{s}\left(R_{t}^{F}\right)=\frac{1}{T_{s}} \sum_{t: D_{t}^{a}=0} R_{t}^{F}, \hat{\mathbb{E}}_{c}\left(R_{t}^{F}\right)=\frac{1}{T_{c}} \sum_{t: D_{t}^{a}=1} R_{t}^{F}, T_{s}$, and $T_{c}$ are the number of auctions in non pure complements and pure complements regimes, respectively.

The estimates of the sunk cost parameter, $\alpha$, are statistically significant in all specifications. Given the choice of parameterization for sunk costs, the parameter estimates can be interpreted as the percentage loss in terms of a complete unit of water (Section 2). For our estimate in column 3 this represents a loss of 4.6 pesetas (using the mean value of 152.9 pesetas for a complete unit).

requirement (Song 2004), this would require imposing further structure on the distribution of beliefs in our model (to interpret auctions where, for example, three different farmers win auctions), which is outside the scope of this investigation. Moreover, we only observe winning bids in the data (see Section 3). 
As regards the relative size of the sunk cost with respect to DMR in each regime, we fail to reject the following null hypothesis at the $5 \%$ level:

$$
\begin{aligned}
& H_{0}: \frac{\hat{\alpha}}{3}>\hat{\beta}_{0}^{C}+\hat{\beta}_{1}^{C} \hat{\mathbb{E}}_{c}\left(R_{t}^{F}\right) \\
& H_{0}: \frac{\hat{\alpha}}{3}<\hat{\beta}_{0}^{S}+\hat{\beta}_{1}^{S} \hat{\mathbb{E}}_{s}\left(R_{t}^{F}\right)
\end{aligned}
$$

The estimated coefficients for covariates have the expected sign. For specification 3, for instance, prices in August (February) are significantly 234 pesetas higher (11 pesetas lower) than on January. This is consistent with the conventional wisdom that water is more (less) valuable during these months because of high (low) water demand. Also as expected, past rain decreases equilibrium prices. For specification in column 3, an increase in the average rainfall by $1 \mathrm{~mm}$ from the previous week (with respect to the day of irrigation), decreases average conditional price of a unit of water by 1.7 pesetas.

Participation cost are recovered using data where auctions were run with farmers present, but no bids were placed, along with the identifying restriction that holds in such cases. ${ }^{35}$ Out of the 3,203 auctions where no bids were placed (Table A3 in Subsection C.2 in the Online Appendix), we use the 2,423 where some bidders where present (auctions similar to the one in Figure 5). The interval estimate we obtain using specification 3, $(0.0082<\hat{c}<0.1431)$, is in line with the intuition from the model (hassle or opportunity costs because farmers value their time) and the value used in the econometric specification (0.01).

In comparison of columns $1-2$ and $3-4$, it is clear that the model with covariates outperforms the model without them, as shown by the significance of past rain and seasonal dummy estimates, as well as the increase in the likelihood function, and the improvement in the goodness of the fit. The main reason is the dependence of prices on seasonal factors which we capture in our specification with seasonal dummy variables. From the residual analysis we find no evidence that the increase in the log likelihood function is due to the parametric misspecification of the value distribution itself. Our specification survives the Kolmogorov-Smirnov test, so that the exponential distribution of private valuations cannot

\footnotetext{
${ }^{35}$ See equation A.7 in Section E in the Online Appendix.
} 
Figure 5: Auction Sample: Auction where Farmers Are Present and No Bids Are Placed

\begin{tabular}{c|l|c|c} 
Auction \# & Name & Price & Day \\
\hline 1 & Sebastian Aguilar & 48 & \\
2 & Felipe Amaro & 42 & Mo \\
3 & Felipe Amaro & 48 & \\
4 & Diego Guirao & 50 & \\
\hline 5 & Felipe Amaro & 54 & \\
6 & Antonio Llamas & 51 & \multirow{2}{*}{$\mathrm{Tu}$} \\
7 & Cristobal Romero & 47 & \\
8 & Cristobal Romero & 50 & \\
\hline 9 & Cristobal Gutierrez & 2 & \\
10 & Cristobal Gutierrez & 5 & We \\
11 & Cristobal Gutierrez & 1 & \\
12 & Cristobal Gutierrez & 1 & \\
\hline 13 & Luis Moya & 2.75 & \\
14 & Luis Moya & 1 & \multirow{2}{*}{$\mathrm{Th}$} \\
15 & Luis Moya & 1 & \\
16 & Luis Moya & 1 & \\
\hline 17 & & & \\
18 & & & $\mathrm{Fr}$ \\
19 & & &
\end{tabular}

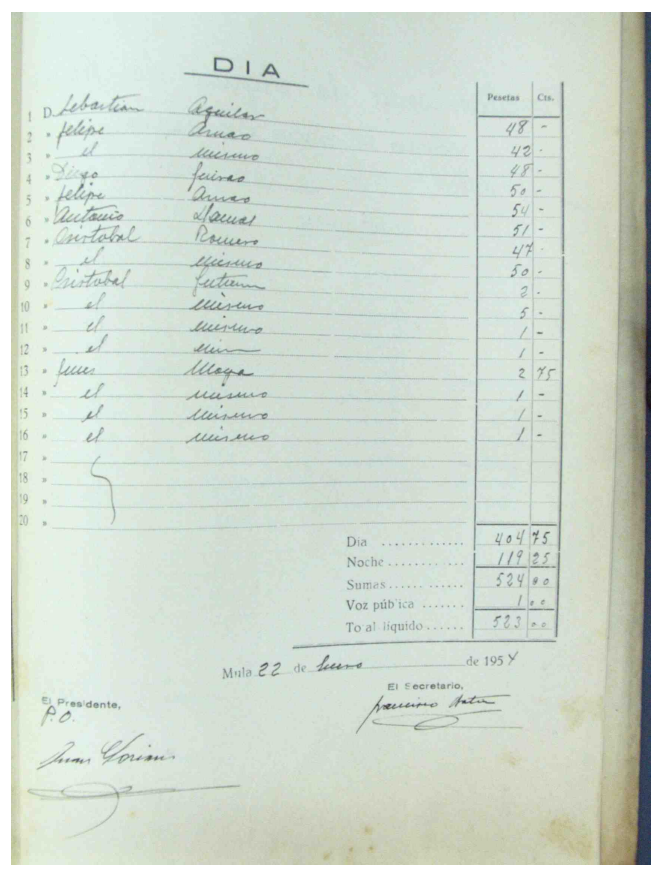

Sample from original data obtained from the historical archive: Auction where farmers are present and no bids are placed (Winter - January 22, 1954, Day).

be rejected (for the specification in column 3 the $p$-value of the test is $39 \%$ ). ${ }^{36}{ }^{37}$

As regards the goodness-of-fit, our specification in column 3 performs quite well, being the pseudo $-R^{2}=53 \%$ (obtained by computing predicted prices by our model: pseudo $-R^{2}=$ $1-\frac{\sum_{t=1}^{T}\left(p_{t}-\hat{p_{t}}\right)^{2}}{\sum_{t=1}^{T}\left(p_{t}-\bar{p}\right)^{2}}$, where $\hat{p}_{t}$ are prices predicted by the model and $\bar{p}$ is the mean of prices). These results are in line with the $R^{2}$ obtained in the reduced-form regressions. Although not directly comparable given the distribution assumptions in the structural approach, the $R^{2}=23 \%$ in the reduced-form specification with all covariates (column 3 in Table A6 in Subsection C.2 in the Online Appendix) can be heuristically interpreted as the proportion of variability in the data set that is accounted for by the covariates, while the proportion accounted by the model without covariates in column 1 in Table 3 is $R^{2}=28 \%$. ${ }^{38}$ As can

\footnotetext{
${ }^{36}$ We perform the nonparametric test to evaluate the equality of two distributions of valuations: our sample of private values with a reference from an exponential distribution.

${ }^{37}$ Also, as a robustness check, we tested that residuals from the estimated model (with covariates) display no correlation with any of the covariates (available in the earlier working paper Donna and Espin-Sanchez 2012).

${ }^{38}$ If we additionally add individual fixed effects to the reduced-form specification, the $R^{2}$ just increases from $23 \%$ to $36 \%$ (column 4 in Table A6 in Subsection C.2 in the Online Appendix).
} 


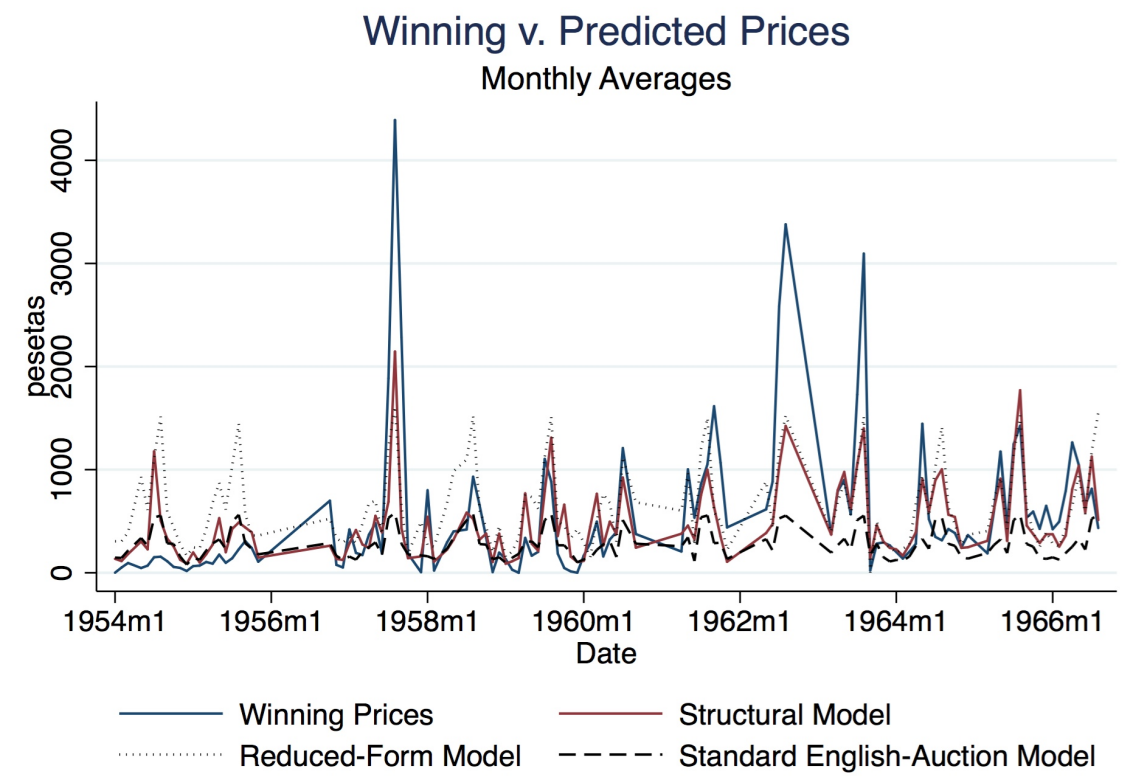

The figure displays real prices against predicted prices using three different models: (i) our structural model (specification 3 in Table 3), (ii) a standard (button) English auction model (specification 5 in Table 3), and (iii) a reduced-form model for the sample using as regressors: Past Rain, unit (3 dummy variables), weekday (4 dummy variables), schedule (1 dummy variable), month (11 dummy variables), year (12 dummy variables), and individual fixed effects, in addition to a constant (for details about the reduced-form specification see Table A6 in Subsection C.2 in the Online Appendix). The graph shows the mean monthly averages of the prices. Similar results are obtained using a spline (available in our earlier working paper Donna and Espin-Sanchez 2012). See Subsection C.4 in the Online Appendix for a high definition version of this figure.

be seen in Figure 6, our model allows us to follow winning prices accurately. ${ }^{39}$ The figure displays real prices against predicted prices using three different models: (i) our structural model (specification 3 in Table 3), (ii) a standard English auction model (specification 5 in Table 3, that we discuss in next subsection), and (iii) a reduced-form model (specification 4 from Table A6 in Subsection C.2 in the Online Appendix that includes Past Rain and multiple fixed effects as regressors such as individual fixed effects).

\subsection{Understanding the Importance of the Model}

We proceed now to analyze our model's implications with respect to the importance of sunk costs (SC) and decreasing marginal returns (DMR). Suppose that the researcher neglects the dynamics that arise from the model and, instead, estimates a standard English auction model. Suppose, for instance, that we are in the pure complements regime (where $\frac{\alpha}{3}>\beta>0$ ),

\footnotetext{
${ }^{39}$ See Subsection C.4 in the Online Appendix for a high definition version of this figure.
} 
and that valuations follow a distribution with mean, $\mu_{v}$, and standard deviation, $\sigma_{v}$. Then, using the result from proposition 11 (see Section A in the Online Appendix), the estimated mean of the distribution of valuations using the standard model, will be underestimated: $\mathbb{E} \hat{\left(v_{i}\right)}{ }^{S M}<\mathbb{E}\left(v_{i}\right)=\mu_{v}$, where SM stands for standard model. Similarly, the estimation of the standard deviation of valuations will overestimated: $\mathbb{V}\left(v_{i}\right)^{S M}>\mathbb{V}\left(v_{i}\right)=\sigma_{v}{ }^{40}$ The same is true in the non pure complements case.

The overestimation of the variance of the distribution is caused by attributing the variation in prices (among different units) to a relatively more disperse underlying distribution. The farmer is actually paying for the whole bundle in the first unit, thus deterring the entrance of other bidders in the remaining three auctions. Failure account for the (common) $\mathrm{SC}$ and DMR in the estimation is the cause for the underestimation of the mean. In the case of the exponential distribution that it is used in our specifications, this will translate into an underestimation of the parameter $\mu$.

Columns 5 and 6 in Table 3 present the estimates from a standard English (button) auction (see proposition 11). Aside from the mentioned bias in the parameter that characterizes the distribution, the results in these columns indicate that taking SC and DMR into account significantly contributes to the explanatory power. Figure 6 shows predicted prices by the standard (button) English auction model (specification 5 in Table 3), and compares them with actual prices and our structural model (specification 3 in Table 3 ). ${ }^{41}$ Consistent with these results, the $p$-value for the null hypothesis that $\hat{\alpha}=\hat{\beta}_{0}^{C}=\hat{\beta}_{0}^{S}=\hat{\beta}_{1}^{C}=\hat{\beta}_{1}^{S}=\hat{c}=0$ is less than $10^{-4}$.

An alternative approach is to ask how the incomplete model approach from Haile and Tamer (2003) can be adapted to the present case. ${ }^{42}$ They rely on two basic assumptions that have intuitive appeal: (i) bidders do not bid more than they are willing to pay for a unit, and (ii) bidders do not allow an opponent to win at a price they are willing to beat. In our case, with SC and DMR, these two simple assumptions are violated. In the pure

\footnotetext{
${ }^{40}$ In the pure complements case and given a fixed number of potential bidders $N$, the (true) mean and variance of the $N-1$ order statistic will be greater than the estimated using the standard model because the (true) price paid will be $\left[4-\alpha-6 \beta_{t, c}\right] v_{N-1: N}-3 c$ and not $4 v_{N-1: N}$ (predicted by the standard model).

${ }^{41}$ See Subsection C.4 in the Online Appendix for a high definition version of this figure.

${ }^{42}$ Larsen (2013) uses a similar approach to Haile and Tamer to obtain bounds about the primitives in an auction model followed by dynamic bargaining with two-sided incomplete information without solving for the equilibrium of the game.
} 
complements regime bidders bid according to $b_{i}^{1}\left(v_{i}\right)=[4-\alpha-6 \beta] v_{i}-3 c>v_{i}$, violating (i), and no bidder (except the highest type) participates in second to four unit auctions, violating (ii) (proposition 8 in Section $\mathrm{A}$ in the Online Appendix). In the non pure complements regime, both assumptions are also violated, though the intuition is different. In this case, the equilibrium is not fully, but partially revealing: bidders' strategies are step functions, so the equilibrium is semi-pooling. When $\alpha$ is greater but close to $\beta$, bidders bid above their valuations to intimidate other bidders and deter entry in the second auction, thus (i) is violated. Additionally, the same argument as in Black and De Meza (1992) and Liu (2011) applies when goods are substitutes: the winner of the first auction imposes a negative externality on himself. His willingness to pay for the second unit is lower than it was for the first unit, making him a weaker bidder in such situation. Given that all bidders will internalize this effect, some of them will bid below their marginal utility for the object in the first auction. The greater are DMR, $\beta$, the greater this effect will be.

Although an adaptation of these assumptions to the whole four-units bundle seems like the natural extension of Haile and Tamer's approach to our case, it is unlikely to produce informative bounds since marginal valuations of the units differ according to the regime and the number of different winners per four-unit auction. Bundling the four-unit or even applying Haile and Tamer's approach separately for each regime, requires the model in Section 2 as an interpretation of the underlying behavior. ${ }^{43}$

Finally, note that Haile and Tamer's results are based on weakly dominant strategies. As we have shown in Section 2, our results are also based on weakly dominant strategies. If we restrict attention to weakly dominant strategies, the standard model - the one analyzed by Haile and Tamer - is a particular case of our model in which $\alpha=\beta=c=0$.

\subsection{Complementarities are not Collusion}

An alternative hypothesis to farmers' behavior in the pure complements regime is that bidders might be playing some collusive (non-competitive) strategy. As emphasized in Section 3 (see also Section $\mathrm{C}$ in the Online Appendix), the demand side of this market for water is composed

\footnotetext{
${ }^{43}$ Note also that failure to consider the effect of the structural parameters (SC and DMR) explicitly introduces difficulties.
} 
by potentially hundreds of farmers (Table 2). Even when they attend the auction and do not bid, the observed number of different winners is relatively high (Figure 5). Because of weather conditions, farmers are competing for water that will ultimately determine the quality and quantity of their crop, and in some cases, even the survival of their trees (drought years). It is unlikely that in this situation farmers can make credible collusive commitments. Contemporaries emphasize the opposite situation: farmers compete aggressively for water (especially during droughts), and water owners are reluctant to lower the price of the water to meet the needs of the poorer farmers. ${ }^{44}$

An important argument against collusion is the high number of non-collusive auctions. Farmers meet every week, hence the discount rate from one week to the next one is close to 1 . If we focus on two consecutive 4-unit auctions, the discount rate is virtually 1 . Thus, any collusive agreement would be easy to sustain and we will observe no "price-wars", or deviations from collusive strategies. If the collusion hypothesis were true, all auctions will look collusive except, perhaps, during certain periods where we will observe price-wars. We observe in many cases, however, that both regimes are present for the same week. Unlike Baldwin, Marshall and Richard (1997) this is not a formal test. ${ }^{45}$

Nevertheless, taking the analysis one step further, if the collusion hypothesis were true (instead of the sunk-and-entry-cost hypothesis), we would expect more collusion in autumnwinter and less collusion in spring-summer. Incentives to deviate from the collusion strategy are higher in spring-summer because the value of the water is higher due to seasonalities (Figures A2 and A5 in Section $\mathrm{C}$ in the Online Appendix). Punishment is about the same in any season: maximum punishment would be to play the competitive equilibrium forever. Future discounted earnings in this case are similar in summer and in winter. Hence, deviating from the collusive strategy is more profitable in summer than in winter. However, the data show exactly the opposite pattern. Figure 7 displays the distribution of auctions in the complementarities regime by month: complementarities are more likely to be observed in summer than in winter, where water requirements (and, hence, equilibrium prices) soar.

\footnotetext{
${ }^{44}$ These opinions, along with a qualitative analysis can be found in Vera Nicolás (2004).

${ }^{45}$ Collusion in repeated auctions has been analyzed conditional (Hopenhayn and Skrzypacz 2004) and unconditional (Porter and Zona 1999 and Pesendorfer 2000) on the history of the game. A discussion on how to detect collusion can be found in Porter (2005).
} 


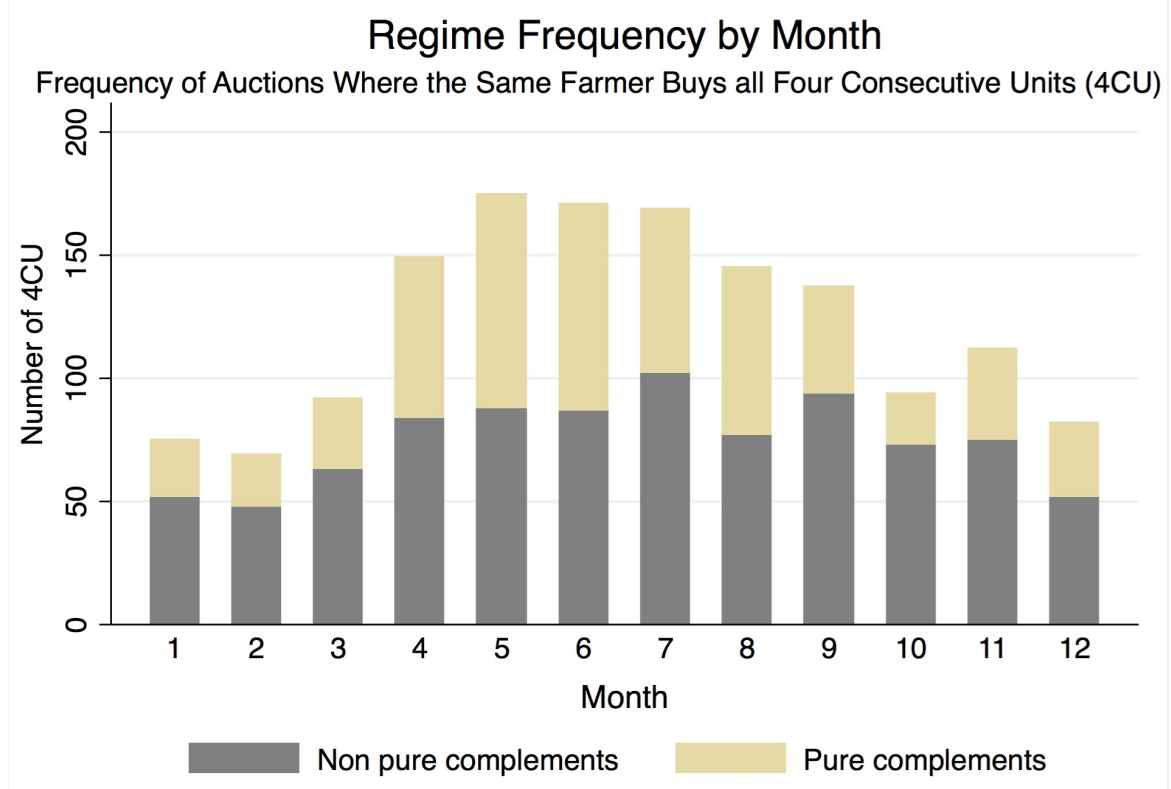

\begin{abstract}
The figure depicts the frequency of auctions where the same farmer buys all four consecutive units (4CU), by regime (see Section $\mathrm{B}$ in the Online Appendix) and month. (Note that the sum of $4 \mathrm{CU}$ over months and regimes - the vertical lines in the graph-is equal to $1470=5880 / 4$. See Tables A3 and A5 in the Online Appendix.) It can be seen that complementarities are more likely to be observed in summer than in winter, where water requirements (and, hence, equilibrium prices) soar. We interpret this as evidence in favor of the competition hypothesis (according to our model with entry and sunk costs) and against the collusion hypothesis.
\end{abstract}

This is in line with our interpretation according to the model with sunk and entry costs described above.

\title{
A "competitive" collusion?
}

When we introduced the model and explained how it fit the data, we implicitly assumed that farmers' plots were sufficiently spaced from each other. Specifically, we assumed that no other farmer could use the same sub-channel that was (just) used by his neighbor. This is not true in reality in some cases. Because the cost of watering the sub-channel is sunk, if the plots of two farmers are located next to each other and they share the same sub-channel, then one farmer could free-ride and outbid the first winner in the second auction. Knowing this, the first winner would bid lower in the first auction. This situation would reduce the revenue of the auction and create inefficiencies. Since farmers might not internalize this free-riding effect, they would take into account the equilibrium outcome for the remaining auctions, and lower their bid in the first auction. They would then will try to outbid their neighbors in later auctions. 
In a situation like the one described above, it would be relatively easy to sustain a collusive agreement among neighboring farmers. The number of members of the coalition would be small (say, three or four farmers), and because they are neighbors, they would know each other well and might even share animals or machinery for agricultural purposes. Each farmer in the coalition would compete in the auction for the first unit, but would not enter the remaining auctions if one member of the coalition won the first unit. With this agreement they would achieve efficiency by solving the free riding problem. With the resulting increase in efficiency, the revenue of the auction would also increase, and the auctioneer would not be opposed to the "collusion". This situation would not affect our results unless farmers coordinate to not outbid neighboring farmers also in the first auction (bidding rings).46 47

\subsection{Efficiency}

The model displayed in Section 2 assumes that it is costly for the bidders to enter the auction. To compare this mechanism (sequential ascending price auction) with other possibilities, this cost has to be taken into account. In this context, and following Stegeman (1996), we interpret this cost as the cost that the farmers have to incur when they send a message to the auctioneer (or to some other farmers). Here, the notions of ex-ante and ex-post efficiency are no longer equivalent, for although it might be ex-ante efficient that more than one player sends a message, it is always ex-post efficient that at most one player sends a message.

For this case, where it is costly to send messages to the coordinator, Stegeman has showed that the ascending price auction has an equilibrium that is ex-ante efficient. In contrast, the first-price auction may have no efficient equilibrium, and the author only considers the singleunit case. In our sequential unit case, we have shown that when goods are pure complements

\footnotetext{
${ }^{46}$ It will only affect the outcome when both the bidder with the highest valuation and the bidder with the second highest valuation belong to the same ring, but the bidder with the third highest valuation belong to a different ring. In this case, our model predicts that the observed price is the valuation of the second highest bidder, but it actually corresponds to the valuation of the third highest bidder. This is unlikely in our empirical setting because the nearly 500 farmers would form around 150 rings (based on the geographical locations that we obtained from the census data). The probability that the two bidders with the highest valuation belong to the same ring is virtually zero. Moreover, the difference between the second highest and the third highest valuation will be small in any case.

${ }^{47}$ There is an extensive literature on the theory of bidding cartels (see, for example, Graham and Marshall 1987; Hendricks, Porter and Guofu (2008); Hopenhayn and Skrzypacz (2004); and McAfee and McMillan 1992). For English auctions, Asker (2010) empirically investigates a bidding cartel of collectable stamps. See Harrington (2008) for a survey.
} 
( $\rho \geq 0$ or $\alpha \geq 3 \beta$ ) the analysis is identical as in the single unit case. Hence, the result applies here as well. However, when goods are non pure complements, the result only applies to the last auction. Although outside the scope of this paper, further work to investigate whether a sequential ascending price auction is ex-post efficient when the coordinator has to allocate several objects to players that face SC, DMR, and costly messages, would be useful for an adequate comparison among other mechanism allocations.

\section{Conclusions}

By affecting bidders' behavior in sequential auctions, the presence of sunk costs and decreasing marginal returns (along with participation costs) generate very different price dynamics within the same market. This difference in price dynamics is attributed to the varying extent to which the value of sequential goods complements or falls relative to previous units. The deterrence effect, where the same bidder pays a high price for the first unit (deterring others from entering subsequent auctions), and a low price for the remaining units, arises when sunk costs are relatively high compared to the decreasing marginal returns, thus creating complementarities among the goods. Substitutability arises due to decreasing returns when sunk costs are relatively small. In this case, equilibrium prices are similar in magnitude, regardless of whether the same or different bidders win the objects. Careful consideration of these features is fundamental to demand characterization, a cornerstone of many positive and normative questions in economics.

Using a novel data set from a decentralized market institution that operated privately for eight centuries in southern Spain, we document these price dynamics and develop a model to recover the underlying structural parameters and distribution of valuations. Although the bidders are better informed than the sellers in our model, the latter know that the sequential English auction allocates water (ex-ante) efficiently. Not requiring farmers to reveal their marginal valuations is an advantage of the mechanism, whose simplicity reduces costs associated with its implementation and helps explain its extraordinary stability. We address three main questions. Are water units complements or substitutes, and why? Is the deterrence effect consistent with a competitive market structure or a consequence of 
collusive behavior among farmers? What would happen to the estimates in this setting if the researcher, by ignoring the importance of participation and sunk costs, failed to account for the complementarity feature of the sequential goods?

First we document that in the period under study, both complementarities and substitutabilities are observed in the data, generating two different equilibrium price dynamics. Seasonality, related to the water requirements of the crops and the expected rainfall, affects the relative importance of sunk costs and decreasing returns, causing bidders to coordinate their actions in these regimes. Second, the apparent collusive behavior, where the same bidder wins all the goods, paying very low prices for all the units following the first unit, is actually competitive (non-cooperative). Contrary to the collusion hypothesis, this behavior is caused by complementarities, and is observed when the value of water (as well as the average price paid per unit and, thus, the incentive to deviate from a collusion strategy) increases relative to the standard competitive pattern registered in the non-complements regime. This shows the importance of interpreting the data through the economic model. Finally, by estimating our model, we confirm the relevance of participation and sunk costs in our empirical environment. By testing the performance of our model relative to a standard English auction model without participation costs, we confirm that estimations using the latter are not accurate. Aside from the bias generated by ignoring sunk costs and decreasing returns, price dynamics play an important role, as it is not appropriate to attribute the variation in prices among sequential units (when the goods are complements) to a relatively more disperse underlying distribution of valuations.

\section{References}

Anton, James J., and Denis A. Yao. 1987. "Second Sourcing and the Experience Curve: Price Competition in Defense Procurement." RAND Journal of Economics.

Aradillas-López, Andrés, Amit Gandhi, and Daniel Quint. 2013. "Identification and Inference in Ascending Auctions with Correlated Private Values." Econometrica, 81: 489-534.

Armstrong, Mark. 2000. "Optimal Multi-Object Auctions." Review of Economic Studies, 455-481.

Arnold, Barry C., Narayanaswamy Balakrishman, and H. N. Nagaraja. 1992. A First Course in Order Statistics. New York:Wiley \& Sons.

Ashenfelter, Orley. 1989. "How Auctions Work for Wine and Art." Journal of Economic Perspectives, 3: 23-36. 
Ashenfelter, Orley, and David Genesove. 1992. "Testing for Price Anomalies in Real-Estate Auctions." American Economic Review, 82: 501-505.

Asker, John. 2010. "A Study of the Internal Organization of a Bidding Cartel." American Economic Review, 100: $724-762$.

Athey, Susan, and Philip A. Haile. 2002. "Identification of Standard Auction Models." Econometrica, 70: $2107-2140$.

Athey, Susan, Jonathan Levin, and Enrique Seira. 2011. "Comparing Open and Sealed Bid Auctions: Theory and Evidence from Timber Auctions." Quarterly Journal of Economics, 126: 207-257.

Ausubel, Lawrence M. 2004. "An Efficient Ascending-Bid Auction for Multiple Objects." American Economic Review, 94: 1452-1475.

Bajari, Patrick, Stephanie Houghton, and Steve Tadelis. 2013. "Bidding for Incomplete Contracts: An Empirical Analysis of Adaptation Costs." forthcoming American Economic Review.

Baldwin, Laura H., Robert C. Marshall, and Jean-Francois Richard. 1997. "Bidder Collusion at Forest Service Timber Sales." Journal of Political Economy, 105: 657-699.

Benhardt, Dan, and David Scoones. 1994. "A Note on Sequential Auctions." American Economic Review, 84.

Black, Jane, and David De Meza. 1992. "Systematic Price Differences between Successive Auctions Are No Anomaly." Journal of Economics 83 Management Strategy, 1: 607-28.

Branco, Fernando. 1997. "Sequential Auctions with Synergies: An Example." Economic Letters, 54: 159163.

Cassady, Ralph. 1967. Auctions and Auctioneering. Berkeley:University of California Press.

Chott, George, and Lucy Bradley. 1997. "Irrigation Needs of Citrus." Maricopa County (Ariz.) Publication No. MC1\%.

Coman, Katharine. 1911. "Some Unsettled Problems of Irrigation." American Economic Review, 1: 1-19.

Cramton, Peter, Yoav Shoham, and Richard Steinberg. 2006. Combinatorial Auctions. Cambridge, MA:MIT PRess.

Donald, Stephen G., and Harry J. Paarsch. 1993. "Piecewise Pseudo-Maximum Likelihood Estimation in Empirical Models of Auctions." International Economic Review, 34.

Donald, Stephen G., and Harry J. Paarsch. 1996. "Identification, Estimation, and Testing in Parametric Empirical Models of Auctions within the Independent Private Values Paradigm." Econometric Theory, 12: $517-567$.

Donna, Javier, and Jose-Antonio Espin-Sanchez. 2012. "Complements and Substitutes in Sequential Auctions: The Case of Water Auctions." Working Paper, The Ohio State University. Available online at http: //dl. dropbox. com/u/4794458/JMP_Donna.pdf.

Donna, Javier, and Jose-Antonio Espin-Sanchez. 2013. "Let the Punishment Fit The Criminal." Working Paper, The Ohio State University. Available online at https://dl. dropboxusercontent. com/u/ 4794458/_ WebPage/Papers/Punishment. pdf. 
du Preez, M. 2001. "Irrigation of Citrus With Reference to Water Shortages and Poor Water Quality." Agricultural Consulters International.

Edelman, Benjamin, Michael Ostrovsky, and Michael Schwarz. 2007. "Internet Advertising and the Generalized Second Price Auction: Selling Billions of Dollars Worth of Keywords." American Economic Review, 97: 242-259.

Engelbrecht-Wiggans, Richard. 1993. "Optimal Auctions Revisited." Games and Economic Behavior, 5: $227-239$.

Engelbrecht-Wiggans, Richard. 1994. "Sequential Auctions of Stochastically Equivalent Objects." Economic Letters, 44: 87-90.

Gandal, Neil. 1997. "Sequential Auctions of Interdependent Objects: Israeli Cable Television Licenses." The Journal of Industrial Economics, 227-244.

Gentzkow, Matthew. 2007. "Valuing New Goods in a Model with Complementarity: Online Newspapers." American Economic Review, 3: 713-744.

González-Castaño, Juan, and Pedro Llamas-Ruiz. 1991. "El Agua en la Ciudad de Mula, S. XVI-XX." Comunidad de Regantes Pantano de la Cierva, Mula, 3.

Graham, Daniel, and Robert Marshall. 1987. "Collusive Bidder Behavior at Single-Object Second-Price and English Auctions." Journal of Political Economy, 95: 1217-39.

Guerre, Emmanuel, Isabelle Perrigne, and Quang Vuong. 2000. "Optimal Nonparametric Estimation of First-Price Auctions." Econometrica, 68: 525-574.

Haile, Philip. 2001. "Auctions with Resale Markets: An Application to U.S. Forest Service Timber Sales." American Economic Review, 91: 399-427.

Haile, Philip A., and Elie Tamer. 2003. "Inference with an Incomplete Model of English Auctions." Journal of Political Economy, 111: 1-51.

Harrington, Joseph E., Jr. 2008. "Detecting Cartels." In: Handbook of Antitrust Economics, ed. Paolo Buccirossi, Cambridge, MA: MIT Press, 213-58.

Hendricks, Kenneth, and Robert H. Porter. 1988. "An Empirical Study of an Auction with Asymmetric Information." American Economic Review, 78: 865-883.

Hendricks, Kenneth, and Robert H. Porter. 2007. "Chapter 32 An Empirical Perspective on Auctions." In: M. Armstrong and R. Porter, Editor(s), Handbook of Industrial Organization, Elsevier, 3: $2073-2143$.

Hendricks, Kenneth, Robert H. Porter, and Tan Guofu. 2008. "Bidding Rings and the Winner's Curse: The Case of Federal Offshore Oil and Gas Lease Auctions." RAND Journal of Economics, 4: 10181041.

Hickman, Brent R., Timothy P. Hubbard, and Yigit Saglam. 2011. "Structural Econometric Methods in Auctions: A Guide to the Literature." Journal of Econometric Methods, 1.

Hopenhayn, Hugo, and Andrzej Skrzypacz. 2004. "Tacit Collusion in Repeated Auctions." Journal of Economic Theory, 114: 153-169. 
Hortaçsu, Ali. 2011. "Recent Progress in the Empirical Analysis of Multi-Unit Auctions." International Journal of Industrial Organization, 29: 345-349.

Jeitschko, Thomas, and Elmar Wolfstetter. 2002. "Scale Economies and the Dynamics of Recurring Auctions." Economic Inquiry, 40: 403-414.

Jofre-Bonet, Mireira, and Martin Pesendorfer. 2003. "Estimation of a Dynamic Auction Game." Econometrica, 1443-1489.

Jofre-Bonet, Mireira, and Martin Pesendorfer. 2012. "Optimal Sequential Auctions." Working Paper, LSE.

Kagel, John H. 1995. "Auctions: A Survey of Experimental Research." in J. Kagel and A. Roth, eds., Handbook of Experimental Economics. Princeton, N.J.: Princeton University Press, 501-85.

Kagel, John H., and Dan Levin. 2001. "Behavior in Multi-Unit Demand Auctions: Experiments with Uniform Price and Dynamic Vickrey Auctions." Econometrica, 69: 413-454.

Kagel, John H., and Dan Levin. 2005. "Multi-Unit Demand Auctions with Synergies: Behavior in SealedBid versus Ascending-Bid Uniform-Price Auctions." Games and Economic Behavior, 53: 170-207.

Kastl, Jakub. 2011. "Discrete Bids and Empirical Inference in Divisible Good Auctions." Review of Economic Studies, 78: 974-1014.

Krasnokutskaya, Elena. 2011. "Identification and Estimation in Highway Procurement Auctions under Unobserved Auction Heterogeneity." Review of Economic Studies, 78: 293-327.

Laffont, Jean-Jacques, Herve Ossard, and Quang Vuong. 1995. "Econometrics of First-Price Auctions." Econometrica, 63: 953-980.

Larsen, Bradley. 2013. "The Efficiency of Dynamic, Post-Auction Bargaining: Evidence from Wholesale Used Auto Auctions." Working Paper, Stanford University.

Levin, Jonathan. 1997. "An Optimal Auction for Complements." Games and Economic Behavior, 18: 176192.

List, John, Daniel Millimet, and Michael Price. 2004. "Inferring Treatment Status when Treatment Assignment is Unknown: with an Application to Collusive Bidding Behavior in Canadian Softwood Timber Auctions." Technical report, University of Maryland.

Liu, Qingmin. 2011. "Equilibrium of a Sequence of Auctions when Bidders Demand Multiple Items." Economic Letters, 112: 192-194.

Lopomo, Giuseppe. 1998. "The English Auction is Optimal among Simple Sequential Auctions." Journal of Economic Theory, 82: 144-166.

Marshall, Robert, Mathew Raiff, Jean-Francois Richard, and Steven Schulenberg. 2006. "The Impact of Delivery Synergies on Bidding in the Georgia School Milk Market." The B.E. Journal of Economic Analysis \& Policy, 6: 1-51.

McAfee, R. Preston, and Daniel Vincent. 1993. "The Declining Price Anomaly." Journal of Economic Theory, 60: 191-212. 
McAfee, R. Preston, and John McMillan. 1987. "Auctions with Entry." Economic Letters, 23: 343-7.

McAfee, R. Preston, and John McMillan. 1992. "Bidding Rings." American Economic Review, 82: 57999.

Milgrom, Paul. 2000. "Putting Auction Theory to Work: The Simultaneous Ascending Auction." The Journal of Political Economy, 245-272.

Milgrom, Paul, and Robert Weber. 1982. "A Theory of Auctions and Competitive Bidding." Econometrica, 50: 1089-1122.

Ostrom, Elinor. 1992. Crafting Institutions for Self-Governing Irrigation Systems. San Francisco, CA:ICS Press.

Palfrey, Thomas. 1983. "Bundling Decisions by a Multiproduct Monopolist with Incomplete Information." Econometrica, 463-484.

Pesendorfer, Martin. 2000. "A Study of Collusion in First Price Auctions." Review of Economic Studies, 67: 381-411.

Porter, Robert H. 2005. "Detecting Collusion." Review of Industrial Organization, 26: 147-167.

Porter, Robert H., and J. Douglas Zona. 1999. "Ohio School Milk Markets: An Analysis of Bidding." RAND Journal of Economics, 30: 263-288.

Reguant, Mar. 2013. "Complementary Bidding Mechanisms and Startup Costs in Electricity Markets." Working Paper, Stanford University.

Roberts, James. 2009. "Unobserved Heterogeneity and Reserve Prices in Auctions." Duke Working Paper.

Somaini, Paulo. 2013. "Identification in Auction Models with Interdependent Costs." Mimeo, Stanford University.

Song, Unjy. 2004. "Nonparametric Estimation of an eBay Auction Model with an Unknown Number of Bidders." Mimeo, University of British Columbia.

Stegeman, Mark. 1996. "Participation Costs and Efficient Auctions." Journal of Economic Theory, 71: 228259.

Vera Nicolás, Pascual. 2004. Murcia y el Agua: Historia de Una Pasión. Murcia:Academia Alfonso X El Sabio. Available online at http://servicios.laverdad.es/murcia_agua/.

von der Fehr, Nils-Henrik. 1994. "Predatory Bidding in Sequential Auctions." Oxford Economic Papers, 46: $345-356$.

Weber, Robert. 1983. "Multiple-Object Auctions." in R. Engelbrecht-Wiggans, R.M. Stark, M. Shubik., eds., Auctions, Bidding and Contracting, New York: NYU Press, 165-691.

Wolfram, Catherine. 1998. "Strategic Bidding in a Multi-Unit Auction: an Empirical Analysis of Bids to Supply Electricity in England and Wales." RAND Journal of Economics, 703-725.

Wright, Glenn. 2000. "Irrigating Citrus Trees." The Universty of Arizona, College of Agriculture, Publication No. AZ1151, 46: 1-5.

Zulehner, Christine. 2009. "Bidding Behavior in sequential Cattle Auctions." International Journal of Industrial Organization, 27: 33-42. 